Article

\title{
Mixed Zinc/Manganese on Highly Reduced Graphene Oxide: A Highly Active Nanocomposite Catalyst for Aerial Oxidation of Benzylic Alcohols
}

\author{
Mohamed E. Assal 1, Mohammed Rafi Shaik ${ }^{1}$, Mufsir Kuniyil 1,2, Mujeeb Khan ${ }^{1}$, \\ Abdulrahman Yahya Alzahrani ${ }^{3}$, Abdulrahman Al-Warthan ${ }^{1}$, Mohammed Rafiq H. Siddiqui 1,* \\ (iD) and Syed Farooq Adil 1,* \\ 1 Department of Chemistry, College of Science, King Saud University, P.O. 2455, Riyadh 11451, Saudi Arabia; \\ mhd.elshahat@gmail.com (M.E.A.); rafiskm@gmail.com (M.R.S.); mufsir@gmail.com (Muf.K.); \\ kmujeeb@ksu.edu.sa (Muj.K.); awarthan@ksu.edu.sa (A.A.-W.) \\ 2 Department of Chemistry, K. L. University, Guntur 522502, Andhra Pradesh, India \\ 3 Petrochemical Research Centre, King Abdul-Aziz City for Science and Technology, Riyadh 11451, \\ Saudi Arabia; aalzahrani@kacst.edu.sa \\ * Correspondence: rafiqs@ksu.edu.sa (M.R.H.S.); sfadil@ksu.edu.sa (S.F.A.); \\ Tel.: +966-11-4676-082 (M.R.H.S.); +966-11-4670-439 (S.F.A)
}

Received: 29 November 2017; Accepted: 12 December 2017; Published: 15 December 2017

\begin{abstract}
Nanocomposites of highly reduced graphene oxide (HRG) and $\mathrm{ZnO}_{\mathrm{x}}$ nanoparticles doped manganese carbonate containing different percentages of HRG were prepared via a facile co-precipitation method. The prepared sample calcined at $300{ }^{\circ} \mathrm{C}$ yielded i.e., $\mathrm{ZnO}_{\mathrm{x}}(1 \%)-\mathrm{MnCO}_{3} /(\mathrm{X} \%) \mathrm{HRG}$ (where $\left.\mathrm{X}=0-7\right)$, calcination at $400{ }^{\circ} \mathrm{C}$ and $500{ }^{\circ} \mathrm{C}$, yielded different manganese oxides i.e., $\mathrm{ZnO}_{\mathrm{x}}(1 \%)-\mathrm{MnO}_{2} /(\mathrm{X} \%) \mathrm{HRG}$ and $\mathrm{ZnO}_{\mathrm{x}}(1 \%)-\mathrm{Mn}_{2} \mathrm{O}_{3} /(\mathrm{X} \%) \mathrm{HRG}$ respectively. The prepared catalyst were subjected to catalytic evaluation and a comparative catalytic study between carbonates and oxides for the liquid-phase aerobic oxidation of benzylic alcohols to corresponding aldehydes using molecular oxygen as an eco-friendly oxidant without adding additives or bases. The influence of various parameters such as percentage of HRG, reaction time, catalyst amount, calcination and reaction temperature was systematically examined to optimize reaction conditions using oxidation of benzyl alcohol as a substrate model. It was found that the catalytic performance is remarkably enhanced after using HRG as catalyst co-dopant for the aerobic oxidation of alcohols, possibly owing to the presence of carbon defects and oxygenated functional groups on HRG surface. The as-synthesized catalysts were characterized by SEM, EDX, XRD, Raman, TGA, BET, and FT-IR. Under optimal conditions, the catalyst with composition $\mathrm{ZnO}_{\mathrm{x}}(1 \%)-\mathrm{MnCO}_{3} /(1 \%) \mathrm{HRG}$ calcined at $300{ }^{\circ} \mathrm{C}$ exhibited remarkable specific activity $\left(57.1 \mathrm{mmol} \cdot \mathrm{g}^{-1} \cdot \mathrm{h}^{-1}\right)$ with $100 \%$ conversion of benzyl alcohol and more than $99 \%$ product selectivity within extremely short time $(7 \mathrm{~min}$ ). The as-prepared catalyst was re-used up to five consecutive times without significant decrease in its activity and selectivity. To the best of our knowledge, the achieved specific activity is the highest so far compared to the earlier reported catalysts used for the benzyl alcohol oxidation. A wide range of substituted benzylic and aliphatic alcohols were selectively oxidized into their corresponding aldehydes with complete convertibility and selectivity in short reaction times without over-oxidation to the acids. Due to their significant low cost, superior reproducibility, excellent catalytic efficiency, the $\mathrm{ZnO}_{\mathrm{x}}(1 \%)-\mathrm{MnCO}_{3} /(\mathrm{X} \%) \mathrm{HRG}$ nanocomposites possess several application prospect in other organic chemistry reactions.
\end{abstract}

Keywords: $\mathrm{ZnO}_{\mathrm{x}}$ nanoparticles (NPs); highly reduced graphene oxide; nanocomposite; aerial oxidation 


\section{Introduction}

Selective oxidation of aromatic and aliphatic alcohols to their corresponding carbonyl compounds is a significant and fundamental organic transformation because the carbonyl compound i.e., aldehyde and ketone derivatives formed are important starting material/intermediate in the confectionaries, perfumery, food, dyestuffs, cosmetics, and pharmaceutical industries [1-5]. Nevertheless, oxidation of alcohols into corresponding aldehydes and ketones via conventional methods not only includes harmful, toxic, corrosive oxidizing agents such as (chromate, hypochlorite or permanganate etc.) and harsh condition (such as high temperature and pressure), and also produces a large quantity of contaminant and toxic by-products [6-9]. With increasing environmental concerns, enormous efforts have been made to develop some green processes to overcome these drawbacks [10,11]. Therefore, selective oxidation of alcohols by green approaches using heterogeneous catalysis has gained special attention from the economic and environmental points of view [12-14].

Several studies have been reported using precious metals such as Au [15], Pd [16], Pt [17] and $\mathrm{Ru}$ [18] as a catalyst for the aerobic oxidation of alcohols with high catalytic activities and selectivities, often these catalysts have disadvantages owing to being expensive, difficulty in preparation, and rarity of these noble metals that limit their applications [19]. Therefore, use of series of plentiful and cheaper transition metals such as copper [20], cobalt [21], nickel [22], iron [23], vanadium [24], silver [25], chromium [26], molybdenum [27], rhenium [28] and zirconium [29] as catalysts for the oxidation of alcohols to their corresponding aldehydes or ketones is still in demand and also, metal and/or metal oxide nanoparticles catalysts were found to be very effective and efficient for the aerial oxidation of alcohols. Moreover, it has been extensively reported that the catalytic performance of metal oxide nanoparticles catalysts remarkably improved upon doping with other metals probably due to the synergistic effects between metal and metal oxide nanoparticles as well as the significant augmentation of the surface area [30].

Particularly, manganese carbonate $\left(\mathrm{MnCO}_{3}\right) /$ manganese oxide is considered one of the inexpensive and most stable metal oxides with high catalytic performance and have been commonly used as a catalyst or catalyst support for the selective oxidation of alcohols into their corresponding carbonyl compounds due to various advantages such as high activity, stable, inexpensive and environmentally friendly catalyst [31,32]. Additionally, various types of manganese oxide, mixed manganese oxide, noble metal doped/supported manganese oxides were employed for the oxidative conversions of several organic moieties such as naphthalene to carbon dioxide $\left(\mathrm{CO}_{2}\right)$ [33], carbon monoxide to $\mathrm{CO}_{2}$ [34], toluene to $\mathrm{CO}_{2}$ [35], olefins to olefins oxide/epoxide [36], ethylene and propylene to $\mathrm{CO}_{2}$ [37], cyclohexane to cyclohexanol and cyclohexanone [38], oxidation of benzene to $\mathrm{CO}_{2}$ and $\mathrm{CO}$ [39], oxidation of alkyl aromatics to ketones [40], nitrogen monoxide to nitrogen dioxide [41], 4-tert-butyltoluene to 4-tert-butylbenzaldehyde [42] and formaldehyde to $\mathrm{CO}_{2}$ [43].

Graphene a single atomically thin layer of $\mathrm{sp} 2$ hybridized carbon atoms in a honeycomb crystal two-dimensional (2D) lattice [44], has been reported for wide range of applications including engineering, electronics, energy storage, drug delivery, lithium ion batteries, gas storage, water purification, sensors, supercapacitor, solar cells, and catalysis [45-51]. In recent years, HRG has received growing interest as promising material for heterogeneous catalyst supports for a plethora of graphene-based metal and metal oxide nanocomposites such as Pd NPs/rGO [52], GO-FePc [53], $\gamma-\mathrm{MnO}_{2} / \mathrm{GO}$ [54] Ag NPs/rGO [55], Au NPs/HRG [56], Pt NPs/HRG [57], rGO/MnCoO [58], $\mathrm{Fe}_{3} \mathrm{O}_{4}-\mathrm{Pt} / \mathrm{rGO}$ [59] and $\mathrm{TiO}_{2} / \mathrm{HRG}$ [60], AuPd-GO/ $\mathrm{TiO}_{2}$ [61] for the liquid phase selective oxidation of alcohols to corresponding carbonyl compounds.

In continuation of our efforts on the use of various mixed metal oxide nanoparticles as an efficient catalyst for the aerobic oxidation of benzylic and aliphatic alcohols [15,25,30,52,62], we report here, a simple and straightforward procedure for the synthesis of $\mathrm{ZnO}_{\mathrm{x}}$ nanoparticles doped manganese carbonates and oxides supported with different percentages of highly reduced graphene and employed for aerial oxidation of alcohols in order to understand the effect of presence of $\mathrm{HRG}$ in the catalytic system (Scheme 1). Nanocomposites of $\mathrm{ZnO}_{\mathrm{x}}(1 \%)-\mathrm{MnCO}_{3} /(\mathrm{X} \%) \mathrm{HRG}$ 
were synthesized and their catalytic activities examined in selective oxidation of alcohols to corresponding aldehydes and ketones via ideal green procedure. To the best of our knowledge, this is the first report on the nanocomposites of $\mathrm{ZnO}_{\mathrm{x}}(1 \%)-\mathrm{MnCO}_{3} /(\mathrm{X} \%) \mathrm{HRG}$ as a catalyst for selective oxidation of alcohols. Moreover, the nanocomposite material was characterized by several techniques such as scanning electron microscopy, energy dispersive X-ray spectroscopy, powder X-ray diffraction, Thermogravimetric analysis, Brunauer-Emmett-Teller analysis, Raman spectroscopy and Fourier-transform infrared spectroscopy.

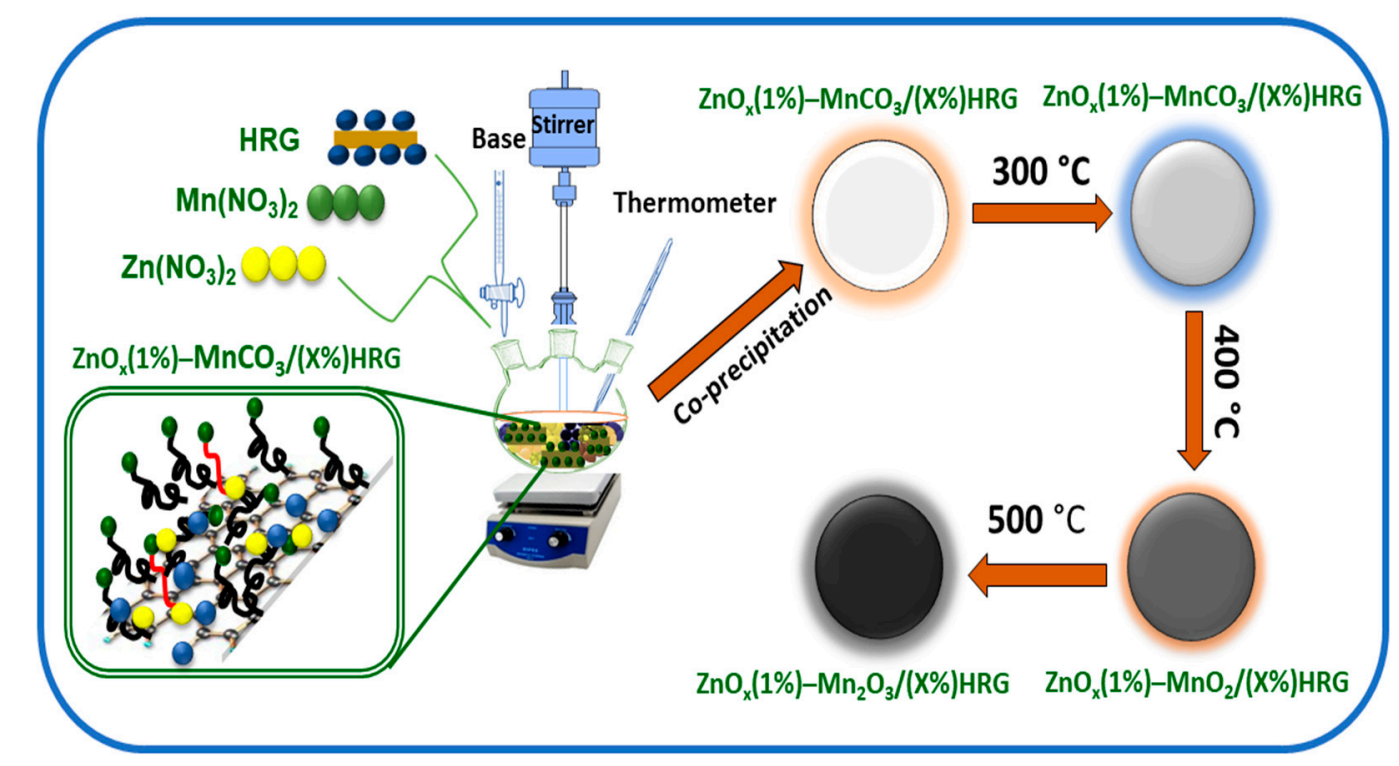

Scheme 1. Graphical representation of the preparation of $\mathrm{ZnO}_{\mathbf{x}}(1 \%)-\mathrm{MnCO}_{3} /(\mathrm{X} \%) \mathrm{HRG}, \mathrm{ZnO}_{\mathbf{x}}(1 \%)-\mathrm{MnO}_{2} /$ $(\mathrm{X} \%) \mathrm{HRG}$, and $\mathrm{ZnO}_{\mathrm{x}}(1 \%)-\mathrm{Mn}_{2} \mathrm{O}_{3} /(\mathrm{X} \%) \mathrm{HRG}$ nanocomposites.

\section{Results and Discussion}

\subsection{Characterization of Catalysts}

\subsubsection{X-ray Diffraction Analysis (XRD)}

The crystalline structures of pristine graphite, graphene oxide (GO), highly reduced graphene oxide (HRG), $\mathrm{ZnO}_{\mathrm{x}}(1 \%)-\mathrm{MnCO}_{3}$, and $\mathrm{ZnO}_{\mathrm{x}}(1 \%)-\mathrm{MnCO}_{3} /(1 \%) \mathrm{HRG}$ nanocomposite were examined by XRD. As shown in Figure 1a, graphite powder displays an intense and sharp peak at $2 \theta=26.5^{\circ}$ which corresponds to the diffraction peak of (002) crystal plane with a interlayer spacing of $3.37 \AA$ [63]. However, GO exhibits broad diffraction peak at $2 \theta=11.8^{\circ}$ which is a characteristic of GO (Figure $1 b$ ). The disappearance of the graphite peak at $2 \theta=26.5^{\circ}$ and appearance of a new peak at $2 \theta=11.8^{\circ}$, indicates the formation of GO via graphite oxidation $[64,65]$. This shift leads to an increase in an inter planar distance from $3.37 \AA$ to $6.41 \AA$ for graphite and GO, respectively, which can be attributed to the inclusion of several oxygenated functional groups and water molecules between the graphite sheets during the oxidation process $[64,66]$. XRD pattern of HRG exhibited a broad peak at approximately $2 \theta=24.6^{\circ}$ which is a characteristic structure of HRG and disappearance of diffraction peak at $2 \theta=11.8^{\circ}$, confirms the complete reduction of GO as descried in Figure 1c [67]. The XRD pattern of $\mathrm{ZnO}_{\mathrm{x}}(1 \%)-\mathrm{MnCO}_{3} /(1 \%) \mathrm{HRG}$ nanocomposite displayed a broad peak around $2 \theta=24.6^{\circ}$, the characteristic diffraction signal of HRG along with the diffraction pattern of rhodochrosite D- $\mathrm{MnCO}_{3}$ (JCPDS No.: 1-0981) [68], indicating the formation of a composite (Figure 1e). As expected the characteristic broad peak of $\mathrm{HRG}$ at $2 \theta=24.6^{\circ}$ (Figure 1d) is not found in the XRD pattern of unsupported $\mathrm{ZnO}_{\mathrm{x}}(1 \%)-\mathrm{MnCO}_{3}$ which has the diffraction pattern of rhodochrosite D- $\mathrm{MnCO}_{3}$ (JCPDS 
No.: 1-0981). The used catalyst after 5 cycles of reuse was characterized by XRD and no significant change was observed in the XRD pattern of the used catalyst (Figure S1, Supplementary Materials).

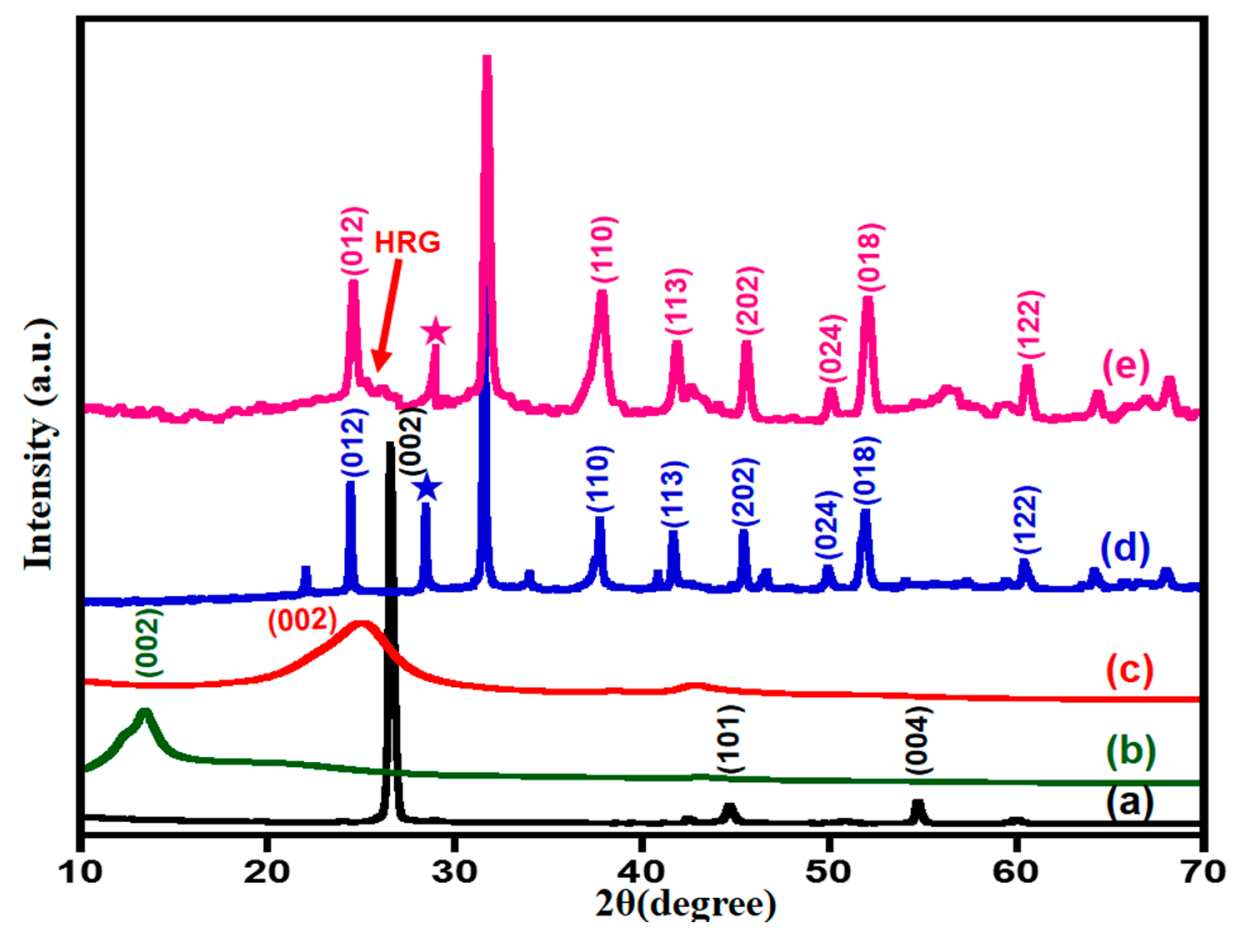

Figure 1. XRD patterns of (a) pristine graphite; (b) GO; (c) $\mathrm{HRG}$; (d) $\mathrm{ZnO} \mathrm{O}_{\mathrm{x}}(1 \%)-\mathrm{MnCO}_{3}$; and (e) $\mathrm{ZnO}_{\mathrm{x}}(1 \%)-\mathrm{MnCO}_{3} /(1 \%) \mathrm{HRG}$. The reflections marked with an asterisk $\left(^{*}\right)$ could be attributed to the presence of $\mathrm{ZnO}_{x}$ phase.

\subsubsection{Thermogravimetric Analysis (TGA)}

Thermogravimetric analysis (TGA) is performed to determine the stability of $\mathrm{ZnO}_{\mathrm{x}}(1 \%)-\mathrm{MnCO}_{3} /(1 \%) \mathrm{HRG}$ nanocomposite. TGA confirmed that the simultaneous conversion of graphene oxide (GO) to HRG nanosheets via reduction with hydrazine hydrate as reductant. Figure 2 displays the thermal behavior of pristine graphite, graphene oxide, highly reduced graphene oxide, $\mathrm{ZnO}_{\mathrm{x}}(1 \%)-\mathrm{MnCO}_{3}$, and $\mathrm{ZnO}_{\mathrm{x}}(1 \%)-\mathrm{MnCO}_{3} /(1 \%) \mathrm{HRG}$ nanocomposite samples. As described in Figure 2a,b the thermal stability of GO nanosheets is extremely lower than the pure graphite. Pure graphite sample exhibits a total weight loss of around $1 \%$ in the temperature range (25-800 ${ }^{\circ} \mathrm{C}$ ) as illustrated in Figure 2a $[69,70]$. On the contrary, GO shows $\sim 6 \%$ weight loss around $100{ }^{\circ} \mathrm{C}$, obviously due to the evaporation of absorbed water molecules and volatile impurities. It is followed by a main weight loss of about $43 \%$ due to pyrolysis of the labile oxygen-containing functional groups (hydroxyl, carbonyl, epoxy, and carboxyl groups) in the temperature range of $200-370{ }^{\circ} \mathrm{C}$ [71-73]. Lastly, a weight loss (11\%) occurs in the temperature range of $370-800{ }^{\circ} \mathrm{C}$ owing to the combustion of the carbon skeleton [74]. These results are in good agreement with earlier publications [64,75]. The TGA curve of HRG exhibited total weight loss (19\%) at the identical temperature range because of the reduction of the oxygen containing functional groups (Figure 2c). The $\mathrm{ZnO}_{\mathrm{x}}(1 \%)-\mathrm{MnCO}_{3} /(1 \%) \mathrm{HRG}$ nanocomposite exhibited overall weight loss lower than $23 \%$ in the same temperature range (Figure 2e). However, the $\mathrm{ZnO}_{\mathrm{x}}(1 \%)-\mathrm{MnCO}_{3}$ is found to have better thermal stability with just $17 \%$, suggesting that the incorporation of HRG in the preparation of the nanocomposites decreased its thermal stability. These results indicate effective reduction of GO to HRG by removing most of the oxygen functionalities such as hydroxyl, carboxyl, epoxy, and carbonyl groups. Further in order to ascertain the conversion of manganese carbonate to manganese(IV) oxide and manganese(III) oxide as obtained from calcination of the salts and which was confirmed by XRD, thermal studies were carried out under 
oxygen and the results obtained indicate that the catalyst displays a weight loss of $\sim 22 \%$ up to $400{ }^{\circ} \mathrm{C}$ which corresponds to the conversion of $\mathrm{MnCO}_{3}$ to $\mathrm{MnO}_{2}$, this further converts of $\mathrm{Mn}_{2} \mathrm{O}_{3}$ which is confirmed by a weight loss of $\sim 9 \%$ around $500{ }^{\circ} \mathrm{C}$, supporting the phases obtained during calcination at these temperatures. The thermogram obtained is given in Supplementary Materials (Figure S2).

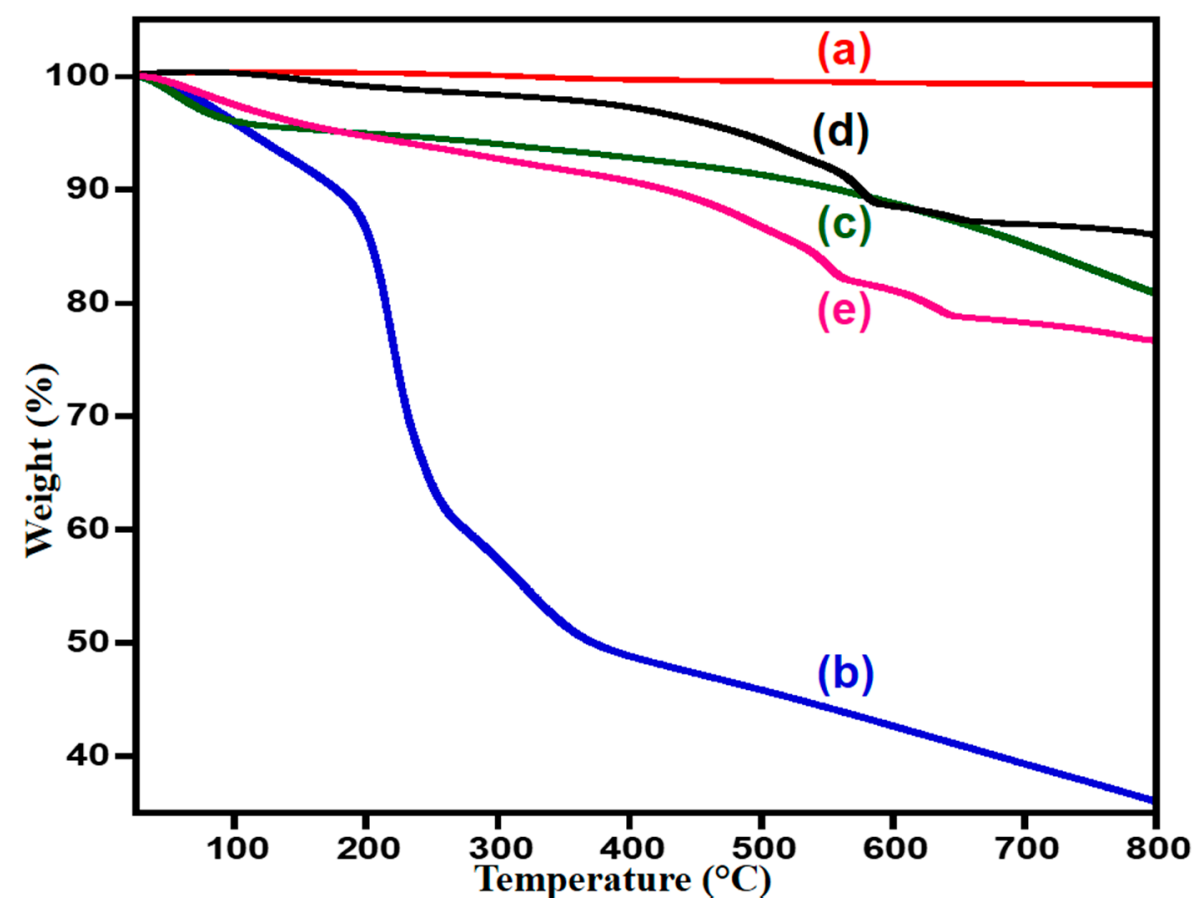

Figure 2. TGA curves of (a) graphite; (b) $\mathrm{GO}$; (c) $\mathrm{HRG}$; (d) $\mathrm{ZnO}_{\mathrm{x}}(1 \%)-\mathrm{MnCO}_{3}$; and (e) $\mathrm{ZnO}_{\mathrm{x}}(1 \%)-\mathrm{MnCO}_{3} /(1 \%) \mathrm{HRG}$.

\subsubsection{Fourier Transforms Infrared Spectrometer (FT-IR)}

Figure 3 presents FT-IR spectrum of GO, HRG, and $\mathrm{ZnO}_{\mathrm{x}}(1 \%)-\mathrm{MnCO}_{3} /(1 \%) \mathrm{HRG}$ samples. The FT-IR spectra of GO (Figure 3a) exhibits an intensive broad peak around $3430 \mathrm{~cm}^{-1}$ assigned to hydroxyl groups $(\mathrm{O}-\mathrm{H})$ stretching vibrations of $(-\mathrm{COOH})$ groups and water molecules [76]. The sharp peak at $1740 \mathrm{~cm}^{-1}$ correspond to $(\mathrm{C}=\mathrm{O})$ stretching of $(-\mathrm{COOH})$ on the surface [77], and the strong absorption peak at approximately $1630 \mathrm{~cm}^{-1}$ is due to the stretching vibration of carbon backbone $(C=C / C-C)[78,79]$. In addition, the three absorption bands located at 1397, 1225, and $1060 \mathrm{~cm}^{-1}$ are assigned to stretching vibrations of $(\mathrm{C}-\mathrm{OH}),(\mathrm{C}-\mathrm{O}-\mathrm{C})$ and $(\mathrm{C}-\mathrm{O})$, correspondingly $[76,80]$. In HRG spectra obtained from the reduction of GO in hydrazine monohydrate (Figure $3 \mathrm{~b}$ ), the broad band around $1214 \mathrm{~cm}^{-1}$ corresponds to $(\mathrm{C}-\mathrm{OH})$ stretching vibration and weak peak around $1634 \mathrm{~cm}^{-1}$ is related to $(\mathrm{C}=\mathrm{C})$ group owing to the skeletal aromatic vibration. Other peaks corresponding to oxygenated functional groups disappeared [64]. FT-IR spectrum of $\mathrm{ZnO}_{x}(1 \%)-\mathrm{MnCO}_{3} /(1 \%) \mathrm{HRG}$ nanocomposite clearly shows that the complete reduction of most of oxygen containing functional groups in the $\mathrm{GO}$ surface (Figure $3 \mathrm{c})$. The strong peaks belong to $(\mathrm{C}=\mathrm{O}),(\mathrm{C}-\mathrm{O}-\mathrm{C})$, and $(\mathrm{C}-\mathrm{O})$ stretching vibrations at 1740,1225 , and $1060 \mathrm{~cm}^{-1}$ were not observed, indicating that the oxygen containing functional groups on GO surfaces were almost removed. In addition to, weak peak at $1634 \mathrm{~cm}^{-1}$ corresponding to $(C=C)$ stretching modes attributed to the skeletal aromatic vibration is observed [81,82]. In addition, two sharp absorption peaks located at 730 and $860 \mathrm{~cm}^{-1}$, and a broad vibration band at $1450 \mathrm{~cm}^{-1}$, are the characteristic absorption peaks of $\mathrm{MnCO}_{3}[83,84]$, these results are in good agreement with XRD data. Meanwhile, absorption band at around $580 \mathrm{~cm}^{-1}$ could be due to different oxides of manganese [85]. 


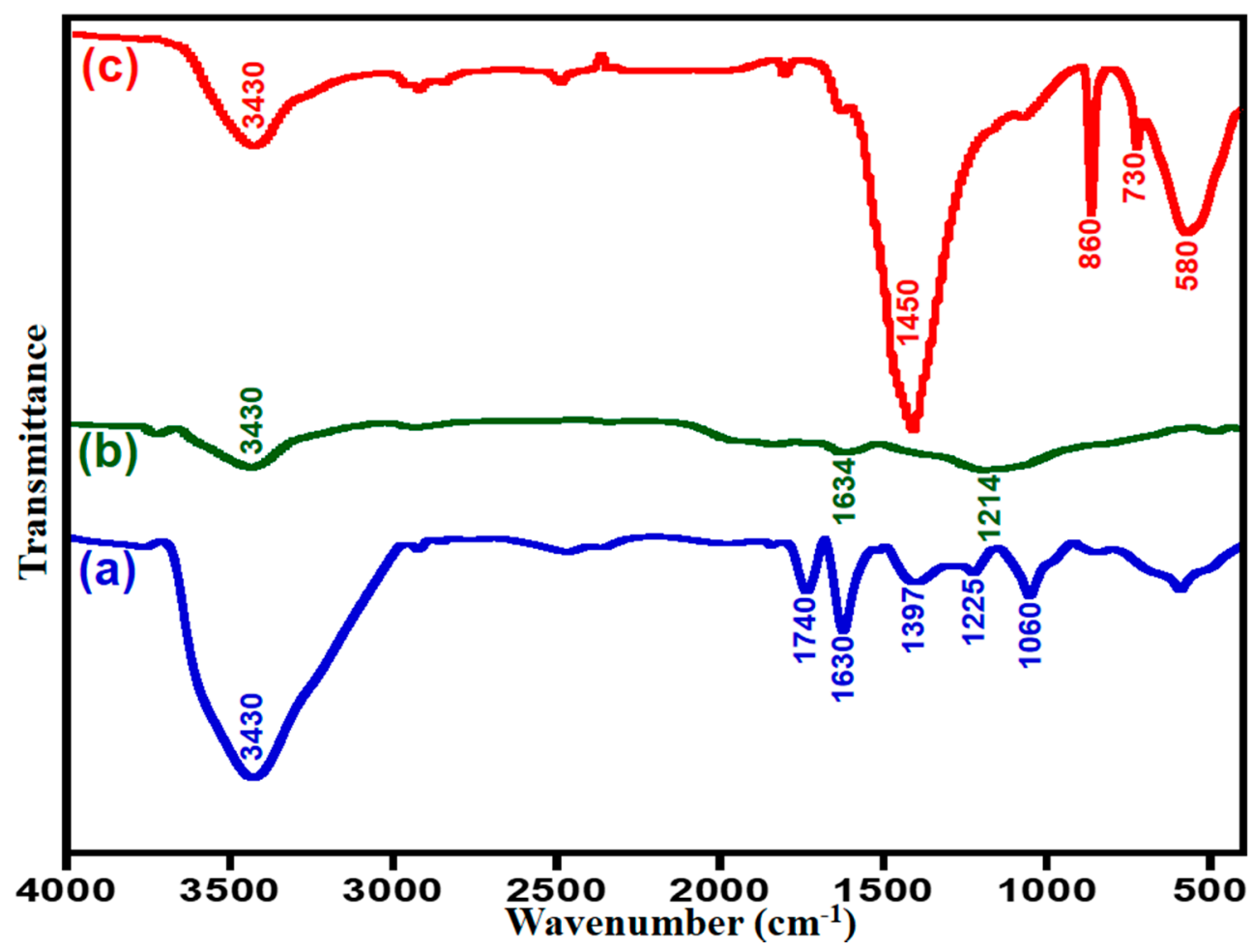

Figure 3. FT-IR spectra of (a) GO; (b) HRG; and (c) $\mathrm{ZnO}_{\mathbf{x}}(1 \%)-\mathrm{MnCO}_{3} /(1 \%) \mathrm{HRG}$ nanocomposite.

\subsubsection{Scanning Electron Microscopy (SEM) and Elemental Analysis (EDX)}

The size and morphology of the as-prepared $\mathrm{ZnO}_{\mathbf{x}}(1 \%)-\mathrm{MnCO}_{3}$ and highly reduced graphene oxide supported $\mathrm{ZnO}_{\mathrm{x}}(1 \%)-\mathrm{MnCO}_{3} /(1 \%) \mathrm{HRG}$ catalyst obtained by co-precipitation is monitored using scanning electron microscope (SEM). Figure 4 displays the SEM images of the un-supported $\mathrm{ZnO}_{x}(1 \%)-\mathrm{MnCO}_{3}$ after calcining at $300{ }^{\circ} \mathrm{C}$ (Figure 4a) and $\mathrm{HRG}$ supported $\mathrm{ZnO}_{\mathrm{x}}(1 \%)-\mathrm{MnCO}_{3} /(1 \%) H R G$ (Figure $\left.4 \mathrm{~b}\right)$. The $\mathrm{ZnO}_{\mathrm{x}}(1 \%)-\mathrm{MnCO}_{3}$ catalyst shows micro size but well-defined cuboidal shape particles but $\mathrm{HRG}$ supported $\mathrm{ZnO}_{\mathrm{x}}(1 \%)-\mathrm{MnCO}_{3} /(1 \%) \mathrm{HRG}$ (Figure $4 \mathrm{~b}$ ), shows aggregation of rather smaller size crystals which appear to have grown on the surface through surface nucleation/growth process. The elemental composition of the as-fabricated catalyst is determined using energy dispersive $X$-ray spectroscopy (EDX) analysis and stays within experimental error to the theoretical composition (Table 1).
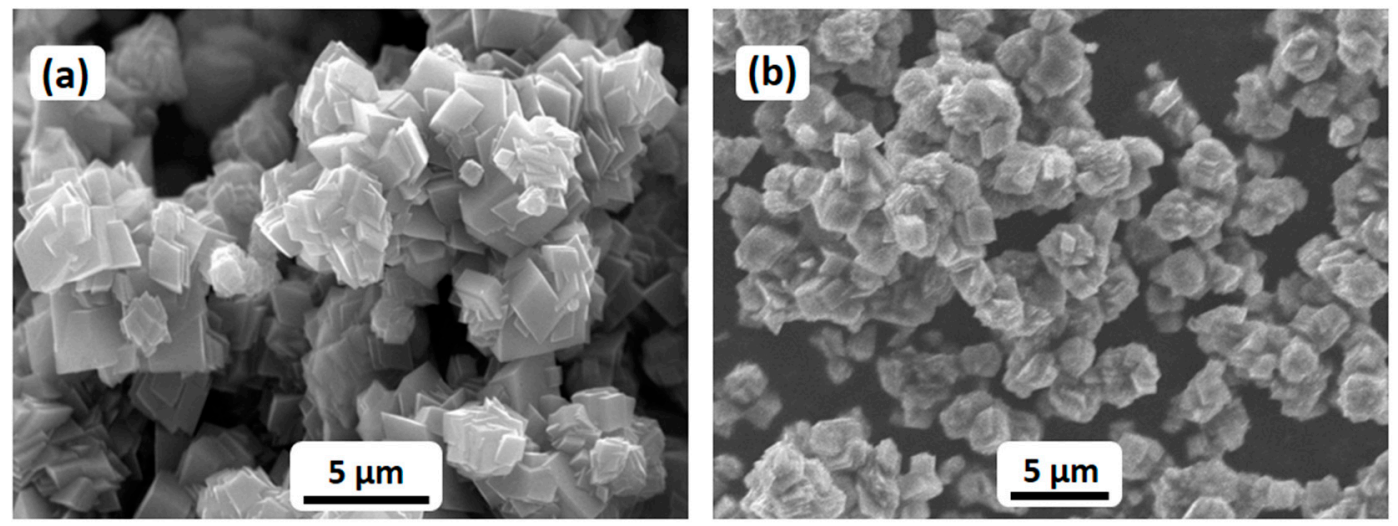

Figure 4. SEM micrographs of (a) $\mathrm{ZnO}_{\mathrm{x}}(1 \%)-\mathrm{MnCO}_{3}$; and (b) $\mathrm{ZnO}_{\mathrm{x}}(1 \%)-\mathrm{MnCO}_{3} /(1 \%) \mathrm{HRG}$ nanocomposite. 
Table 1. Elemental composition of the catalyst $\mathrm{ZnO}_{\mathbf{x}}(1 \%)-\mathrm{MnCO}_{3}$ and $\mathrm{ZnO}_{\mathbf{x}}(1 \%)-\mathrm{MnCO}_{3} /(1 \%) \mathrm{HRG}$.

\begin{tabular}{ccccc}
\hline \multirow{2}{*}{ Catalyst } & \multicolumn{4}{c}{ Element Mass (\%) } \\
\cline { 2 - 5 } & $\mathbf{C}$ & $\mathbf{O}$ & Mn & Zn \\
\hline $\mathrm{ZnO}_{\mathbf{x}}(1 \%)-\mathrm{MnCO}_{3}$ & 6.30 & 23.65 & 69.04 & 1.01 \\
$\mathrm{ZnO}_{\mathrm{x}}(1 \%)-\mathrm{MnCO}_{3} /(1 \%) \mathrm{HRG}$ & 26.03 & 40.33 & 32.52 & 1.12 \\
\hline
\end{tabular}

\subsubsection{Raman Spectra}

Raman spectroscopy is a very informative characterization instrument for studying the structure of graphene and its derivatives. Figure 5 shows the Raman spectrum of graphene oxide (GO), $\mathrm{ZnO}_{\mathrm{x}}(1 \%)-\mathrm{MnCO}_{3}$, and $\mathrm{ZnO}_{\mathrm{x}}(1 \%)-\mathrm{MnCO}_{3} /(1 \%) \mathrm{HRG}$. Raman spectra of $\mathrm{ZnO}_{\mathrm{x}}(1 \%)-\mathrm{MnCO}_{3}$, and $\mathrm{ZnO}_{\mathrm{x}}(1 \%)-\mathrm{MnCO}_{3} /(1 \%) \mathrm{HRG}$ nanocomposites exhibited two distinct peaks at 724 and $1086 \mathrm{~cm}^{-1}$ which are a finger-print for $\mathrm{MnCO}_{3}$. This indicates the existence of $\mathrm{MnCO}_{3}$ in the nanocomposite consistent with XRD analysis as displayed in Figure 5b,c [86]. Likewise, the existence of HRG in the $\mathrm{ZnO}_{\mathrm{x}}(1 \%)-\mathrm{MnCO}_{3} /(1 \%) \mathrm{HRG}$ nanocomposite is also confirmed by the Raman spectra. For this purpose, the Raman spectra of $\mathrm{ZnO}_{\mathrm{x}}(1 \%)-\mathrm{MnCO}_{3} /(1 \%) \mathrm{HRG}$ is compared with that of $\mathrm{GO}$, as described in Figure 5a. For the synthesized $\mathrm{ZnO}_{x}(1 \%)-\mathrm{MnCO}_{3} /(1 \%) \mathrm{HRG}$ nanocomposite and GO, two characteristic bands are detected at $\sim 1350$ and $\sim 1590 \mathrm{~cm}^{-1}$ respectively, generally denoted as D-band and G-band [87]. The D-band is associated to the disorder in carbon structure induced by lattice defects and the G-band is related to well-ordered structure $[88,89]$. For GO spectra, the G and the D-bands were shifted and appear at 1605 and $1346 \mathrm{~cm}^{-1}$, respectively, due to the destruction of the $\mathrm{sp}^{2}$ character by the oxidation process and presence of oxygenated functionalities [90]. While, for the spectrum of $\mathrm{ZnO}_{\mathrm{x}}(1 \%)-\mathrm{MnCO}_{3} /(1 \%) \mathrm{HRG}$, the $\mathrm{G}$ characteristic band is shifted by $\sim 11 \mathrm{~cm}^{-1}$ from 1605 to $1594 \mathrm{~cm}^{-1}$, whereas a slight shift is noticed in the D-band from 1346 to $1342 \mathrm{~cm}^{-1}$, which is an important evidence of the effective reduction of graphene oxide to highly reduced graphene oxide [52].

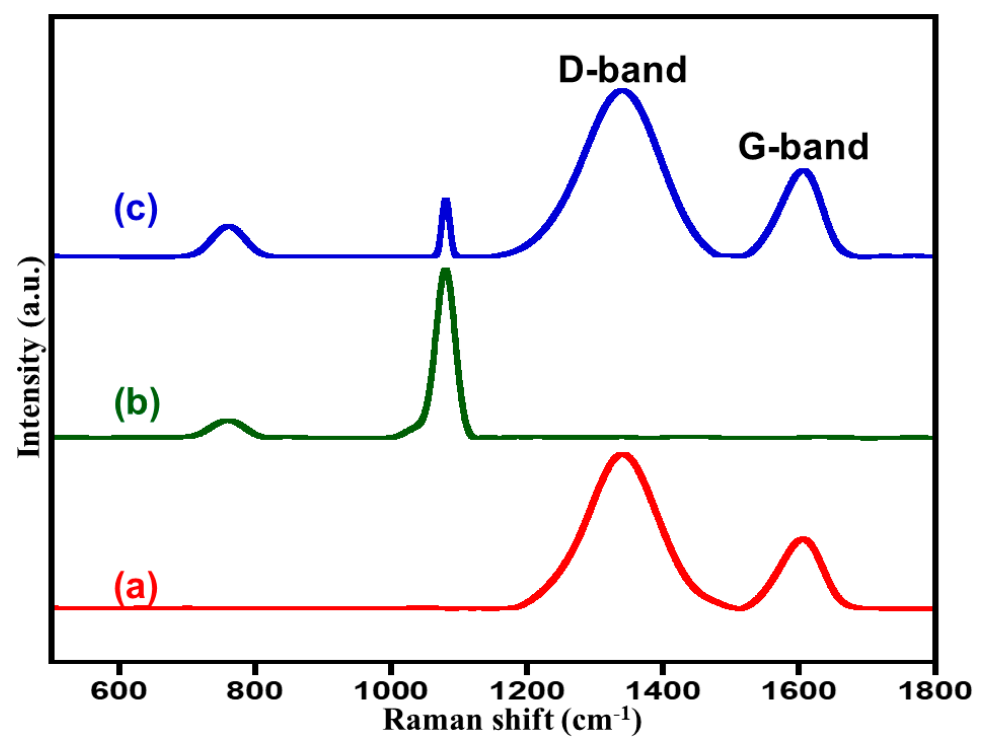

Figure 5. Raman spectra for (a) GO; (b) $\mathrm{ZnO}_{\mathrm{x}}(1 \%)-\mathrm{MnCO}_{3}$; and (c) $\mathrm{ZnO}_{\mathrm{x}}(1 \%)-\mathrm{MnCO}_{3} /(1 \%) \mathrm{HRG}$.

\subsubsection{Surface Area Analysis (BET)}

In order to determine the surface area of the as-prepared catalyst and study its correlation with the performance of the catalytic system for alcohol oxidation, the BET analysis is studied. The specific surface areas of the catalysts $\mathrm{ZnO}_{\mathrm{x}}(1 \%)-\mathrm{MnCO}_{3}, \mathrm{ZnO}_{\mathrm{x}}(1 \%)-\mathrm{MnO}_{2}$, and $\mathrm{ZnO}_{\mathrm{x}}(1 \%)-\mathrm{Mn}_{2} \mathrm{O}_{3}$ without HRG support is about $120.3,69.8$, and $21.8 \mathrm{~m}^{2} \cdot \mathrm{g}^{-1}$ correspondingly as mentioned in the Section 2.2.2. 
While the surface areas of the nanocomposites after using HRG support have increased to 239.1, 179.3, and $131.1 \mathrm{~m}^{2} \cdot \mathrm{g}^{-1}$ respectively. As expected, the surface area of the catalyst prepared using HRG in the catalytic system is higher than the one without HRG and its effect on the catalytic performance on oxidation of benzyl alcohol has been studied and discussed in the later sections.

\subsection{Catalytic Evaluation}

The primary goal of the present work is the employment of the prepared material for oxidation of organic moieties and benzyl alcohol was selected as substrate for the model reaction, using molecular $\mathrm{O}_{2}$ as a clean oxidant (Scheme 2). In order to achieve this objective, we have developed nanocomposites of $\mathrm{HRG}$ and $\mathrm{ZnO}_{x}$ nanoparticles doped $\mathrm{MnCO}_{3}$, which is employed as a catalyst for the aerobic oxidation of benzylic and aliphatic alcohols. It is observed that the oxidation process is significantly influenced by several parameters, such as different percentages of the support (HRG), calcination temperature, catalyst dosage, reaction time, and reaction temperature.

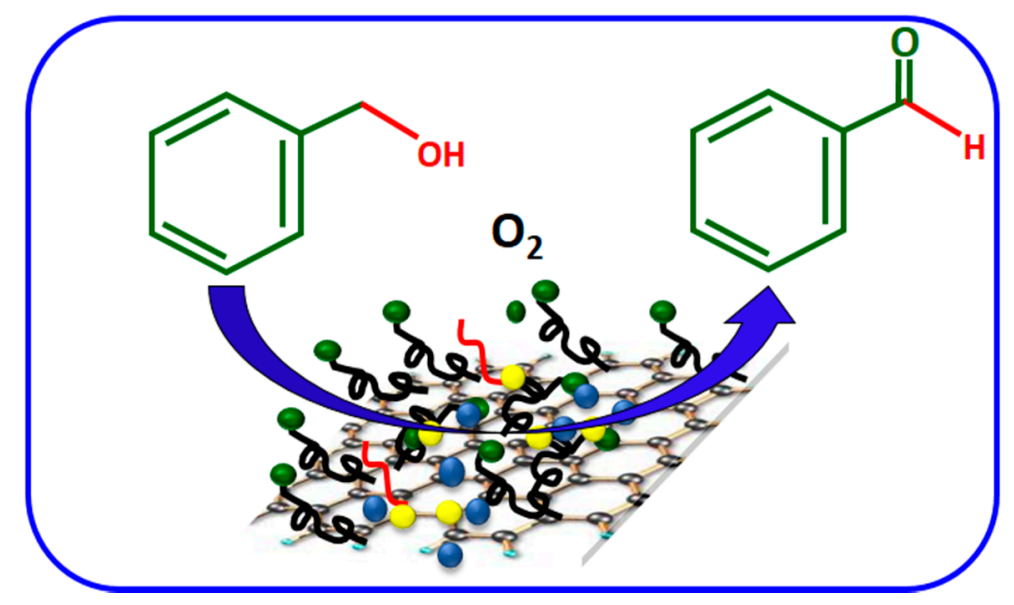

Scheme 2. Aerobic oxidation of benzyl alcohol to benzaldehyde over the as-prepared catalyst.

\subsubsection{Role of HRG on the Catalytic Performance}

The role of the graphene support in the performance of the heterogeneous catalysts for the oxidation of alcohols has been widely examined in these publications [53,67,85,91-96]. From our earlier publication, it was found that $\mathrm{ZnO}_{\mathrm{x}}$ nanoparticles behaved as an excellent promoter in the manganese carbonate catalyst, and the $\mathrm{ZnO}_{x}(1 \%)-\mathrm{MnCO}_{3}$ catalyst was found to be the best among the various catalysts tested for the aerobic oxidation of aromatic alcohols to their corresponding aldehydes [68]. Hence for the current study, the catalyst $\mathrm{ZnO}_{x}(1 \%)-\mathrm{MnCO}_{3}$ is selected with an aim to further modify it by adding HRG to the catalytic system to further enhance its catalytic efficiency. Firstly, efforts were exerted in order to find out the suitable amount of HRG (\%) in the catalyst to enhance the catalytic efficiency.

An experiment using HRG alone as catalyst, is found to yield negligible conversion product i.e., 2.0\%; however when the various\% $\mathrm{HRG}$ is incorporated in the catalytic system, i.e., $\mathrm{ZnO}_{\mathrm{x}}(1 \%)-\mathrm{MnCO}_{3} /(\mathrm{X} \%) \mathrm{HRG}$ nanocomposites where $(\mathrm{X}=0,1,3,5$, and 7$)$, it is found to have a significant influence on the catalytic efficiency. The results were summarized in Table 2 and plotted in Figure 6. From the results obtained it is observed that pure $\mathrm{MnCO}_{3}$ calcined at $300{ }^{\circ} \mathrm{C}$ gave a $42.6 \%$ conversion of benzyl alcohol within $7 \mathrm{~min}$ of the reaction, but after doping it with $1 \%$ of $\mathrm{ZnO}_{\mathrm{x}}$ in $\mathrm{MnCO}_{3}$ i.e., $\mathrm{ZnO}_{\mathrm{x}}(1 \%)-\mathrm{MnCO}_{3}$ (without $\mathrm{HRG}$ ), the catalytic performance remarkably improved, and gave $67.5 \%$ benzyl alcohol conversion under same circumstances (Table 2, entries 2 and 3). However, after further modification with the incorporation of $1 \% \mathrm{HRG}$, the catalyst i.e., $\mathrm{ZnO}_{\mathrm{x}}(1 \%)-\mathrm{MnCO}_{3} /(1 \%) \mathrm{HRG}$ nanocomposite is found to be the best catalyst among all other catalysts including catalysts with increased percentages of $\mathrm{HRG}$. The $\mathrm{ZnO}_{\mathrm{x}}(1 \%)-\mathrm{MnCO}_{3} /(1 \%) \mathrm{HRG}$ catalyst 
exhibited a 100\% benzyl alcohol conversion after short reaction time only $7 \mathrm{~min}$ along with very high specific activity $57.1 \mathrm{mmol} \cdot \mathrm{g}^{-1} \cdot \mathrm{h}^{-1}$ (Table 2, entry 4). Further increasing the percentage of HRG to $3 \%$ led to a slight decrease in the benzyl alcohol conversion to $97.2 \%$ (Table 2, entry 4). While the catalyst with $5 \%$ and $7 \%$ of HRG yielded $85.4 \%$ and $62.7 \%$ conversion product respectively, under identical circumstances (Table 2, entries 6 and 7). It is also found that all the catalysts tested displayed selectivity towards benzaldehyde, which is found to be $>99 \%$ (Table 2, entries 1-7). From the above findings, it can be said that the HRG plays an essential role in enhancing the catalytic performance for the oxidation of benzyl alcohol. The higher activity of $\mathrm{ZnO}_{x}(1 \%)-\mathrm{MnCO}_{3} /(1 \%) \mathrm{HRG}$ nanocomposite, may be ascribed to the chemical adsorption of the aromatic alcohols onto HRG surface via $\pi-\pi$ interaction and reaction with the nearest $\mathrm{ZnO}_{\mathrm{x}}$ nanoparticles anchored onto the HRG nanosheets as well as the increased surface area that can homogenously distribute the active sites of mixed metal oxide $\left(\mathrm{ZnO}_{\mathrm{x}}-\mathrm{MnCO}_{3}\right)$ nanoparticles. In addition, the presence of carbon defects and oxygenic functionalities on HRG surface, which anchored the $\mathrm{ZnO}_{\mathrm{x}}$ nanoparticles, may prevent the agglomeration of graphene layers. Therefore, the $\mathrm{ZnO}_{\mathrm{x}}(1 \%)-\mathrm{MnCO}_{3} /(1 \%) \mathrm{HRG}$ nanocomposite is the best catalysts prepared, based on which $\mathrm{ZnO}_{\mathrm{x}}(1 \%)-\mathrm{MnCO}_{3} /(1 \%) \mathrm{HRG}$ is utilized for the further studies in order to optimize other parameters.

Table 2. Catalytic results of various catalysts in the selective oxidation of benzyl alcohol.

\begin{tabular}{ccccc}
\hline Entry & Catalyst & Conversion (\%) & $\begin{array}{c}\text { Specific Activity } \\
\left(\mathbf{m m o l} \cdot \mathbf{g}^{-\mathbf{1}} \cdot \mathbf{h}^{\mathbf{- 1}} \mathbf{)}\right.\end{array}$ & Selectivity (\%) \\
\hline 1 & $\mathrm{HRG}$ & 2.0 & 1.2 & $>99$ \\
2 & $\mathrm{MnCO}_{3}$ & 42.6 & 24.3 & $>99$ \\
3 & $\mathrm{ZnO}_{\mathbf{x}}(1 \%)-\mathrm{MnCO}_{3}$ & 67.5 & 38.6 & $>99$ \\
4 & $\mathrm{ZnO}_{\mathbf{x}}(1 \%)-\mathrm{MnCO}_{3} /(1 \%) \mathrm{HRG}$ & 100.0 & 57.1 & $>99$ \\
5 & $\mathrm{ZnO}_{\mathbf{x}}(1 \%)-\mathrm{MnCO}_{3} /(3 \%) \mathrm{HRG}$ & 97.2 & 55.6 & $>99$ \\
6 & $\mathrm{ZnO}_{\mathbf{x}}(1 \%)-\mathrm{MnCO}_{3} /(5 \%) \mathrm{HRG}$ & 85.4 & 48.8 & $>99$ \\
7 & $\mathrm{ZnO}_{\mathbf{x}}(1 \%)-\mathrm{MnCO}_{3} /(7 \%) \mathrm{HRG}$ & 62.7 & 35.9 & $>99$ \\
\hline
\end{tabular}

Reaction conditions: catalyst, $300 \mathrm{mg}$; benzyl alcohol, $2 \mathrm{mmol}$; calcination temperature, $300{ }^{\circ} \mathrm{C}$; oxygen flow rate, $20 \mathrm{~mL} \cdot \mathrm{min}^{-1}$, toluene, $10 \mathrm{~mL}$; and $7 \mathrm{~min}$ reaction time.

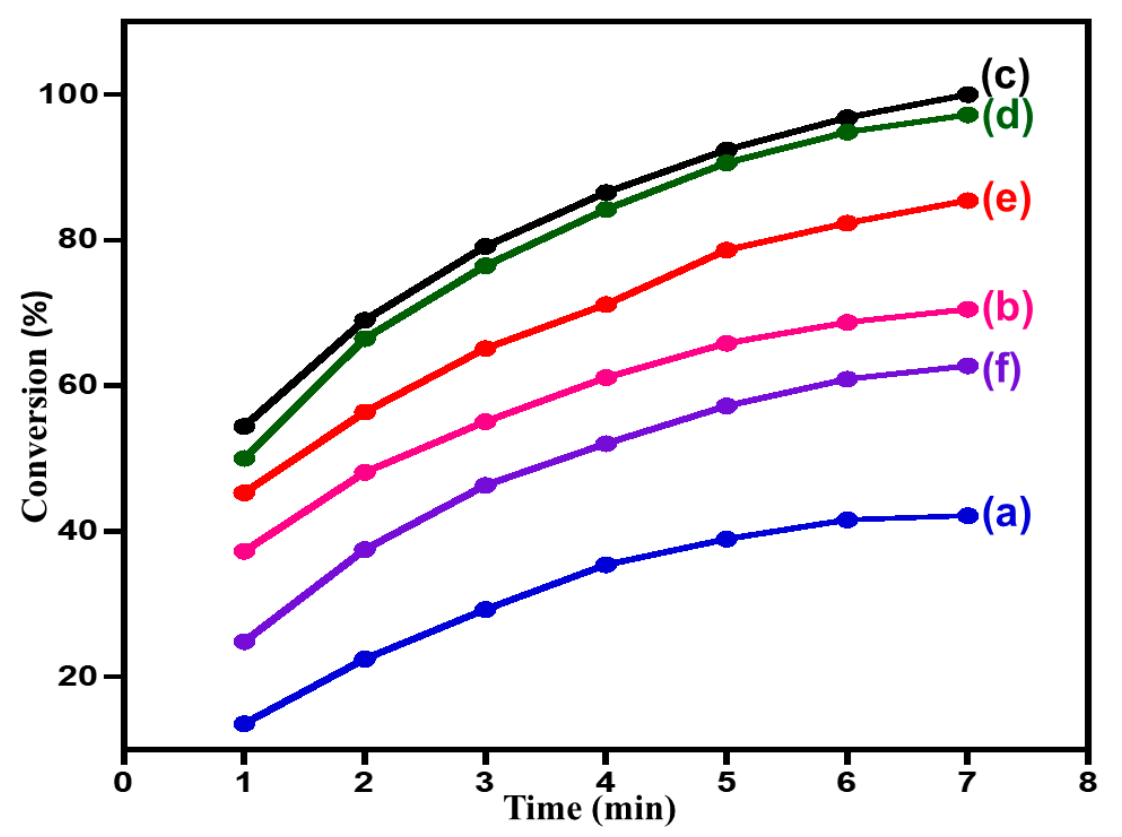

Figure 6. Graphical illustration of benzyl alcohol oxidation using the catalysts (a) $\mathrm{MnCO}_{3}$; (b) $\mathrm{ZnO}_{\mathrm{x}}(1 \%)-\mathrm{MnCO}_{3} ;$ (c) $\mathrm{ZnO}_{\mathrm{x}}(1 \%)-\mathrm{MnCO}_{3} /(1 \%) \mathrm{HRG} ;$ (d) $\mathrm{ZnO}_{\mathrm{x}}(1 \%)-\mathrm{MnCO}_{3} /(3 \%) \mathrm{HRG}$; (e) $\mathrm{ZnO}_{\mathrm{x}}(1 \%)-\mathrm{MnCO}_{3} /(5 \%) \mathrm{HRG}$; and (f) $\mathrm{ZnO}_{\mathrm{x}}(1 \%)-\mathrm{MnCO}_{3} /(7 \%) \mathrm{HRG}$. 


\subsubsection{Influence of Calcination Temperature}

Calcination temperature has a significant effect on the composition of the synthesized catalysts, such as changes in the oxide composition, surface morphology and surface area. These factors in turn, effect the catalytic efficiency of the as-synthesized catalyst. Therefore, the catalytic activity of the as-prepared catalyst calcined at various temperatures $300{ }^{\circ} \mathrm{C}, 400{ }^{\circ} \mathrm{C}$, and $500{ }^{\circ} \mathrm{C}$ is also investigated in order to get the optimum calcination temperature that gives best catalytic performance, the results are summarized in Table 3 and plotted in Figure 7. It is found that the reactivity of benzyl alcohol is substantially affected by calcination treatment. In our previous study it was found that the prepared $\mathrm{ZnO}_{\mathrm{x}}(1 \%)-\mathrm{MnCO}_{3}$ upon calcination at $400{ }^{\circ} \mathrm{C}$ yielded $\mathrm{ZnO}_{\mathrm{x}}(1 \%)-\mathrm{MnO}_{2}$. Calcination at $500^{\circ} \mathrm{C}$ resulted in the formation of $\mathrm{ZnO}_{x}(1 \%)-\mathrm{Mn}_{2} \mathrm{O}_{3}$. Catalytic evaluation, shows the conversion product obtained within $7 \mathrm{~min}$ of reaction time to be $67.5 \%, 40.8 \%$, and $21.9 \%$ respectively (Table 3, entries 1-3). The results indicated that calcination temperature have impeding effect on the oxidation process by decreasing the benzyl alcohol conversion [12]. However in the present study upon the inclusion of $\mathrm{HRG}$ in the catalytic system, the catalyst calcined at $300{ }^{\circ} \mathrm{C}$ i.e., $\mathrm{ZnO}_{\mathrm{x}}(1 \%)-\mathrm{MnCO}_{3} /(1 \%) \mathrm{HRG}$ gave a $100 \%$ conversion of benzyl alcohol with 57.1 specific activity within $7 \mathrm{~min}$ (Table 3, entry 4). While the ones calcined at $400{ }^{\circ} \mathrm{C}$ and $500{ }^{\circ} \mathrm{C}$ i.e., $\mathrm{ZnO}_{\mathrm{x}}(1 \%)-\mathrm{MnO}_{2} /(1 \%) \mathrm{HRG}$ and $\mathrm{ZnO}_{\mathrm{x}}(1 \%)-\mathrm{Mn}_{2} \mathrm{O}_{3} /(1 \%) \mathrm{HRG}$, respectively, yielded $77.2 \%$ and $56.5 \%$ conversion product, respectively under similar conditions (Table 3, entries 5 and 6). Additionally, in case of 400 and $500{ }^{\circ} \mathrm{C}$ calcination temperatures, there is a decrease in specific activity, which gives only 44.1 and $32.3 \mathrm{mmol} \cdot \mathrm{g}^{-1} \cdot \mathrm{h}^{-1}$ with no change with the product selectivity during all oxidation experiments. The catalytic performance has remarkably increased after incorporating the HRG in the catalytic system, which indicated that the graphene plays an essential role in enhancing the efficacy of the catalytic system. Interestingly, these observations also suggest that the surface area of the catalyst also plays an essential role in the catalytic performance of the prepared material. Upon BET analysis of the prepared catalyst the surface area of it is found that the catalyst calcined at $300{ }^{\circ} \mathrm{C}$ i.e., $\mathrm{ZnO}_{\mathrm{x}}(1 \%)-\mathrm{MnCO}_{3} /(1 \%) \mathrm{HRG}$, which yielded a $100 \%$ alcohol conversion product, possesses the highest surface area among the catalyst calcined at $400{ }^{\circ} \mathrm{C}$ and $500{ }^{\circ} \mathrm{C}$, which were found to possess lower surface area and also have yielded lesser benzyl alcohol conversion. The specific surface area in case of 400 and $500{ }^{\circ} \mathrm{C}$ calcination temperature i.e., $\mathrm{ZnO}_{\mathrm{x}}(1 \%)-\mathrm{MnO}_{2} /(1 \%) \mathrm{HRG}$ and $\mathrm{ZnO}_{\mathrm{x}}(1 \%)-\mathrm{Mn}_{2} \mathrm{O}_{3} /(1 \%) \mathrm{HRG}$, respectively have lower surface area, could be due to the sintering. It is noteworthy to mention that sintering not only results inter-particles, but it also minimizes the porosity within a single particle [97]. Thus, it can be concluded that apart from the inclusion of HRG, the catalytic activity is also strongly influenced by calcination treatments of the catalyst. Hence, we used $300{ }^{\circ} \mathrm{C}$ calcination temperature in order to optimize other parameters. The obtained results include benzyl alcohol conversion, surface area, specific activity and selectivity over the catalyst were tabulated in Table 3 and plotted in Figure 7.

Table 3. Effect of the calcination temperature on the catalytic properties.

\begin{tabular}{|c|c|c|c|c|c|c|}
\hline Entry & Catalyst & $\mathrm{T}\left({ }^{\circ} \mathrm{C}\right)$ & $\begin{array}{c}\text { Surface Area } \\
\left(\mathrm{m}^{2} \cdot \mathrm{g}^{-1}\right)\end{array}$ & $\begin{array}{c}\text { Conversion } \\
(\%)\end{array}$ & $\begin{array}{l}\text { Specific Activity } \\
\left(\mathrm{mmol} \cdot \mathrm{g}^{-1} \cdot \mathrm{h}^{-1}\right)\end{array}$ & $\begin{array}{c}\text { Selectivity } \\
(\%)\end{array}$ \\
\hline 1 & $\mathrm{ZnO}_{\mathrm{x}}(1 \%)-\mathrm{MnCO}_{3}$ & 300 & 120.3 & 67.5 & 38.6 & $>99$ \\
\hline 2 & $\mathrm{ZnO}_{\mathrm{x}}(1 \%)-\mathrm{MnO}_{2}$ & 400 & 69.8 & 40.8 & 23.3 & $>99$ \\
\hline 4 & $\mathrm{ZnO}_{\mathrm{x}}(1 \%)-\mathrm{MnCO}_{3} /(1 \%) \mathrm{HRG}$ & 300 & 239.1 & 100.0 & 57.1 & $>99$ \\
\hline 5 & $\mathrm{ZnO}_{\mathrm{x}}(1 \%)-\mathrm{MnO}_{2} /(1 \%) \mathrm{HRG}$ & 400 & 179.3 & 77.2 & 44.1 & $>99$ \\
\hline 6 & $\mathrm{ZnO}_{\mathrm{x}}(1 \%)-\mathrm{Mn}_{2} \mathrm{O}_{3} /(1 \%) \mathrm{HRG}$ & 500 & 131.1 & 56.5 & 32.3 & $>99$ \\
\hline
\end{tabular}

Reaction conditions: catalyst, $300 \mathrm{mg}$; benzyl alcohol, $2 \mathrm{mmol}$; reaction temperature, $100{ }^{\circ} \mathrm{C}$; oxygen flow rate, $20 \mathrm{~mL} \cdot \mathrm{min}^{-1}$; toluene $10 \mathrm{~mL}$; and $7 \mathrm{~min}$ reaction time. 


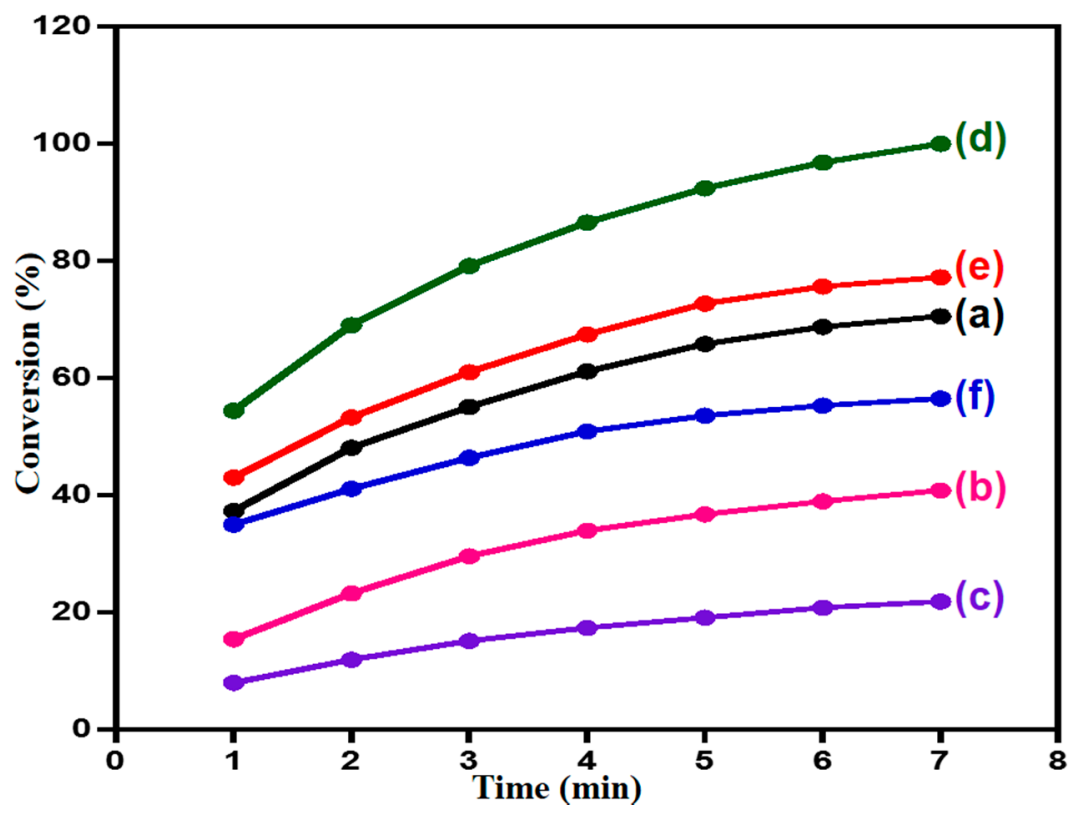

Figure 7. Graphical representation of benzyl alcohol oxidation catalyzed by (a) $\mathrm{ZnO}(1 \%)-\mathrm{MnCO}_{3}$; (b) $\mathrm{ZnO}_{\mathrm{x}}(1 \%)-\mathrm{MnO}_{2} ; \quad$ (c) $\mathrm{ZnO}_{\mathrm{x}}(1 \%)-\mathrm{Mn}_{2} \mathrm{O}_{3} ; \quad$ (d) $\mathrm{ZnO}_{\mathrm{x}}(1 \%)-\mathrm{MnCO}_{3} /(1 \%) \mathrm{HRG} ; \quad$ (e) $\mathrm{ZnO}(1 \%)-$ $\mathrm{MnO}_{2} /(1 \%) \mathrm{HRG}$; and (f) $\mathrm{ZnO}_{\mathrm{x}}(1 \%)-\mathrm{Mn}_{2} \mathrm{O}_{3} /(1 \%) \mathrm{HRG}$.

\subsubsection{Influence of Temperature}

Reaction temperature usually plays a fundamental role in enhancing the effectiveness of the catalytic protocol. The influence of reaction temperature on the aerial oxidation of benzyl alcohol is also explored by varying the temperature from $20{ }^{\circ} \mathrm{C}$ to $100{ }^{\circ} \mathrm{C}$ while using $\mathrm{ZnO}_{\mathrm{x}}(1 \%)-\mathrm{MnCO}_{3} /(1 \%) \mathrm{HRG}$ as catalyst. The obtained results including benzyl alcohol conversion, specific activity, and benzaldehyde selectivity at various temperatures $\left(20,40,60,80\right.$, and $\left.100^{\circ} \mathrm{C}\right)$ were compiled in Table 4 and represented in Figure 8. According to Table 4, the benzyl alcohol conversion strongly depends on the reaction temperature. A low conversion of $43.9 \%$ was obtained at lower temperature $20^{\circ} \mathrm{C}$ (Table 4 , entry 1 ). As expected, the elevated temperature contributed to a higher oxidation rate and led to the remarkable enhance in the catalytic performance of the as-synthesized catalyst. A $100 \%$ conversion of benzyl alcohol is achieved at the temperature of $100{ }^{\circ} \mathrm{C}$ under similar conditions (Table 4, entry 5), whereas the benzaldehyde selectivity still unchanged during all oxidation experiments (above 99\%). The best catalytic activity within the conditions studied is achieved with a reaction temperature of $100{ }^{\circ} \mathrm{C}$, hence is selected for further studies.

Table 4. Effect of reaction temperature on the catalytic evaluation.

\begin{tabular}{ccccc}
\hline Entry & $\begin{array}{c}\text { Reaction } \\
\text { Temperature }\left({ }^{\circ} \mathbf{C}\right)\end{array}$ & Conversion (\%) & $\begin{array}{c}\text { Specific Activity } \\
\left(\mathbf{m m o l} \cdot \mathbf{g}^{-\mathbf{1}} \cdot \mathbf{h}^{-\mathbf{1}} \text { ) }\right.\end{array}$ & Selectivity (\%) \\
\hline 1 & 20 & 43.9 & 25.1 & $>99$ \\
2 & 40 & 58.7 & 33.6 & $>99$ \\
3 & 60 & 73.1 & 41.8 & $>99$ \\
4 & 80 & 86.6 & 49.5 & $>99$ \\
5 & 100 & 100.0 & 57.1 & $>99$ \\
\hline
\end{tabular}

Reaction conditions: benzyl alcohol, $2 \mathrm{mmol}$; calcination temperature, $300{ }^{\circ} \mathrm{C}$; amount the catalyst, $300 \mathrm{mg}$; oxygen flow rate, $20 \mathrm{~mL} \cdot \mathrm{min}^{-1}$; toluene, $10 \mathrm{~mL}$; and $7 \mathrm{~min}$ reaction time. 


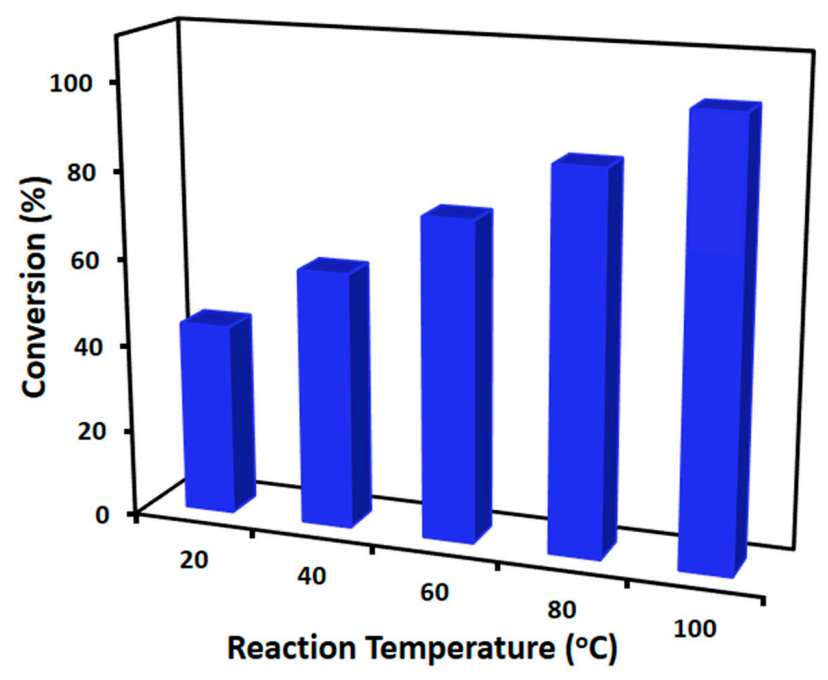

Figure 8. Catalytic activity of $\mathrm{ZnO}_{\mathbf{x}}(1 \%)-\mathrm{MnCO}_{3} /(1 \%) \mathrm{HRG}$ catalyst as a function of reaction temperature.

\subsubsection{Influence of Catalyst Amount}

The influence of the catalyst dosage upon the oxidation of benzyl alcohol is also assessed and the obtained results are illustrated in Figure 9 and listed in Table 5. The amount of $\mathrm{ZnO}_{\mathrm{x}}(1 \%)-\mathrm{MnCO}_{3} /(1 \%) \mathrm{HRG}$ nanocomposite is optimized by employing the reaction with 50,100 , 150, 200, 250 and $300 \mathrm{mg}$ of catalyst under the optimized reaction conditions mentioned earlier. The selectivity towards benzaldehyde is almost unchanged over all oxidation reactions (more than $99 \%$ ). It is noteworthy that effectiveness of catalytic system is directly proportional to the amount of the catalyst. A poor conversion of $19.4 \%$ is obtained in presence of low catalyst amount $(50 \mathrm{mg})$ (Table 5, entry 1), probably due to the fewer catalytic active sites. As expected, by increasing the catalyst amount to $100 \mathrm{mg}$, the conversion of benzyl alcohol also increase to $36.9 \%$ (Table 5, entry 2). When the catalyst amount reaches to $300 \mathrm{mg}$, the catalyst exhibited superior catalytic activity by yielding a complete conversion with the specific activity of $57.1 \mathrm{mmol} \cdot \mathrm{g}^{-1} \cdot \mathrm{h}^{-1}$ after short reaction time $(7 \mathrm{~min}$ ) (Table 5, entry 6). While the rest gave lower than $100 \%$ conversion under same conditions. This study demonstrates that only $300 \mathrm{mg}$ of the catalyst is required for this oxidation reaction to reach a complete conversion of benzyl alcohol to benzaldehyde within short reaction period.

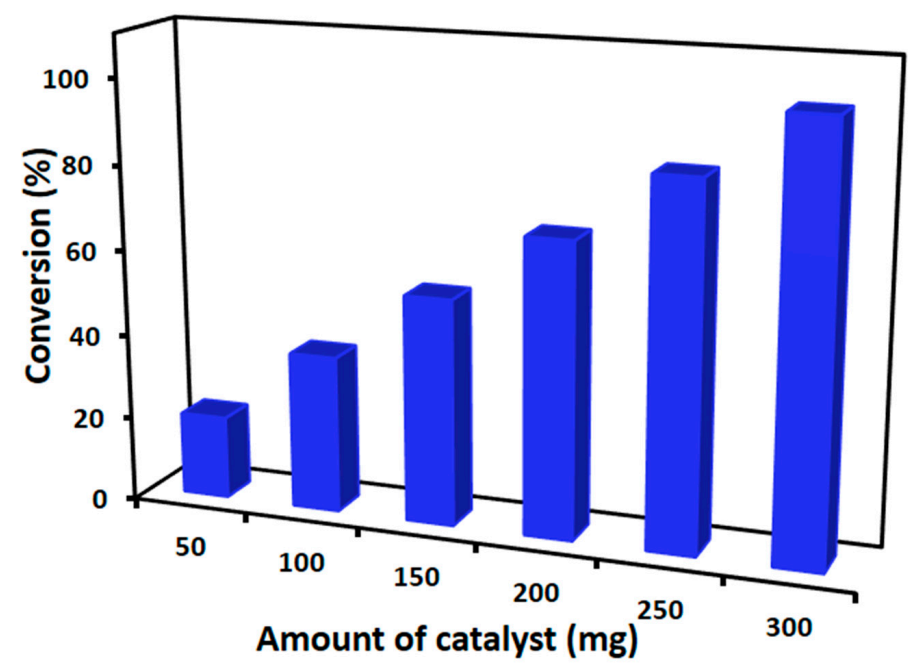

Figure 9. Catalytic performance of $\mathrm{ZnO}_{x}(1 \%)-\mathrm{MnCO}_{3} /(1 \%) \mathrm{HRG}$ catalyst as a function of catalyst amount. 
Table 5. Effect of the catalyst $\mathrm{ZnO}_{x}(1 \%)-\mathrm{MnCO}_{3} /(1 \%) \mathrm{HRG}$ amount on the catalytic performance.

\begin{tabular}{cccccc}
\hline Entry & $\begin{array}{c}\text { Catalyst } \\
\text { Amount }(\mathbf{m g})\end{array}$ & $\begin{array}{c}\text { Conversion } \\
\mathbf{( \% )}\end{array}$ & $\begin{array}{c}\text { Specific Activity } \\
\left(\mathbf{m m o l} \cdot \mathbf{g}^{-\mathbf{1}} \cdot \mathbf{h}^{-\mathbf{1}} \mathbf{)}\right.\end{array}$ & $\begin{array}{c}\text { Substrate/Catalyst } \\
\text { Molar Ratio }\end{array}$ & Selectivity (\%) \\
\hline 1 & 50 & 19.4 & 11.1 & 4.56 & $>99$ \\
2 & 100 & 36.9 & 21.1 & 2.30 & $>99$ \\
3 & 150 & 53.2 & 30.4 & 1.53 & $>99$ \\
4 & 200 & 69.1 & 39.5 & 1.15 & $>99$ \\
5 & 250 & 85.0 & 48.6 & 0.92 & $>99$ \\
6 & 300 & 100.0 & 57.1 & 0.76 & $>99$ \\
\hline
\end{tabular}

Reaction conditions: benzyl alcohol, $2 \mathrm{mmol}$; calcination temperature, $30{ }^{\circ} \mathrm{C}$; reaction temperature, $100{ }^{\circ} \mathrm{C}$; oxygen flow rate, $20 \mathrm{~mL} \cdot \mathrm{min}^{-1}$; toluene, $10 \mathrm{~mL}$; and $7 \mathrm{~min}$ reaction time.

Under similar conditions, a blank experiment performed over the catalyst with only solvent (toluene) in absence of substrate benzyl alcohol in order to prove that there is no role of toluene in the catalytic oxidation of benzyl alcohol and the benzaldehyde product in all oxidation reactions is obtained only from the aerobic oxidation of benzyl alcohol. No formation of benzaldehyde indicates that the aldehyde is from the catalytic oxidation of benzyl alcohol and not from the oxidation of toluene. Similarly, a blank reaction is carried out without the catalyst at the optimum conditions and which also yielded, no conversion product, indicating that the catalyst is necessary for the benzyl alcohol oxidation. In addition, in order to show the significance of molecular $\mathrm{O}_{2}$, the reaction was carried out using $\mathrm{ZnO}_{\mathrm{x}}(1 \%)-\mathrm{MnCO}_{3} /(1 \%) \mathrm{HRG}$ as catalyst in presence of air without bubbling. Under the optimized reaction conditions, the results indicate the formation of $27.3 \%$ conversion of benzyl alcohol, which is far less than the $100 \%$ alcohol conversion obtained when the reaction is performed with molecular $\mathrm{O}_{2}$ bubbling through the reaction mixture.

A comparison of the catalytic performance of present catalyst with the Zn-based catalysts that already reported in the literature is collected in Table 6 to show that the present catalytic system is indeed superior to several of the other systems. By using $\mathrm{ZnO}_{\mathrm{x}}(1 \%)-\mathrm{MnCO}_{3} /(1 \%) \mathrm{HRG}$ nanocomposite, the selective oxidation of benzyl alcohol to benzaldehyde is completed within extremely short reaction time $(7 \mathrm{~min})$ at $100{ }^{\circ} \mathrm{C}$ with $(>99 \%)$ benzaldehyde selectivity and higher specific activity $\left(57.1 \mathrm{mmol} \cdot \mathrm{g}^{-1} \cdot \mathrm{h}^{-1}\right)$ with respect other $\mathrm{Zn}$-based catalysts.

Table 6. Comparison of the $\mathrm{ZnO}_{x}(1 \%)-\mathrm{MnCO}_{3} /(1 \%) \mathrm{HRG}$ catalyst for the oxidation of benzyl alcohol with previously reported $\mathrm{Zn}$-based catalysts.

\begin{tabular}{|c|c|c|c|c|c|c|}
\hline Catalyst & Conversion (\%) & Selectivity (\%) & $\mathrm{T}\left({ }^{\circ} \mathrm{C}\right)$ & Time & $\begin{array}{l}\text { Specific Activity } \\
\left(\mathrm{mmol} \cdot \mathrm{g}^{-1} \cdot \mathrm{h}^{-1}\right)\end{array}$ & Reference \\
\hline $\mathrm{ZnO}_{\mathrm{x}}(1 \%)-\mathrm{MnCO}_{3} /(1 \%) \mathrm{HRG}$ & 100 & $>99$ & 100 & $7 \mathrm{~min}$ & 57.1 & This work \\
\hline $\mathrm{ZnO}_{\mathrm{x}}(1 \%)-\mathrm{MnCO}_{3}$ & 100 & $>99$ & 100 & $0.33 \mathrm{~h}$ & 16.0 & [68] \\
\hline $\mathrm{TCPP} / \mathrm{Zn}-\mathrm{Fe}_{2} \mathrm{O}_{4} @ \mathrm{ZnO}$ & 96 & 100 & reflux & $1.5 \mathrm{~h}$ & 32.0 & [98] \\
\hline $\mathrm{Ag} / \mathrm{ZnO}$ & 98 & $>99$ & 100 & $8 \mathrm{~h}$ & 24.5 & [99] \\
\hline $\mathrm{Zn}-\mathrm{Al} \mathrm{LDH}$ & 100 & 100 & reflux & $2.5 \mathrm{~h}$ & 8.0 & [100] \\
\hline $\mathrm{ZnIn}_{2} \mathrm{~S}_{4}$ & 100 & $>99$ & $\begin{array}{c}\text { room } \\
\text { temperature }\end{array}$ & $2 \mathrm{~h}$ & 6.25 & [101] \\
\hline $\mathrm{Au} / \mathrm{CuO}-\mathrm{ZnO}$ & 94 & $>99$ & reflux & $1 \mathrm{~h}$ & 18.8 & [102] \\
\hline $\mathrm{ZnWO}_{4}$ & 70 & 100 & 70 & $10 \mathrm{~h}$ & 0.7 & [103] \\
\hline$[\mathrm{bmim}]_{5}\left[\mathrm{PW}_{11} \mathrm{ZnO}_{39}\right]$ & 100 & 100 & reflux & $1.25 \mathrm{~h}$ & 16.0 & [104] \\
\hline $\mathrm{PW}_{11} \mathrm{Zn} @ \mathrm{AC}$ & 100 & $>99$ & reflux & $0.75 \mathrm{~h}$ & 6.7 & [105] \\
\hline ZnSA4 & 100 & $>99$ & 80 & $8 \mathrm{~h}$ & 2.5 & [106] \\
\hline $\mathrm{ZnBr}_{2}$ & 100 & 91 & $\begin{array}{c}\text { room } \\
\text { temperature }\end{array}$ & $16 \mathrm{~h}$ & 5.3 & [107] \\
\hline $\mathrm{ZnPW}_{12}$ & 80.1 & 89.1 & 90 & $3.5 \mathrm{~h}$ & 21.7 & [108] \\
\hline $\mathrm{ZnFe}_{2} \mathrm{O}_{4}$ & 6.9 & 95.9 & 90 & $10 \mathrm{~h}$ & 0.6 & [109] \\
\hline $\mathrm{Zn}-\mathrm{Cr}-\mathrm{LDH} / \mathrm{HD}$ & 41.9 & 91.5 & 94 & $5 \mathrm{~h}$ & 8.7 & [110] \\
\hline 1-POM(Zn) & 100 & 100 & reflux & $4.5 \mathrm{~h}$ & 4.4 & [111] \\
\hline $\mathrm{Zn} / \mathrm{Fe}_{2} \mathrm{O}_{4}$ & 100 & 60 & 70 & $6.5 \mathrm{~h}$ & 7.7 & [112] \\
\hline
\end{tabular}

According to data presented in Table 6, other Zn-based catalysts listed take a longer reaction time to complete oxidation of benzyl alcohol, higher reaction temperature or have a lower specific activity. For instance, Golafzani et al. [98] reported liquid phase selective oxidation of benzyl alcohol using TCPP $/ \mathrm{Zn}-\mathrm{Fe}_{2} \mathrm{O}_{4} @ \mathrm{ZnO}$ catalyst via aqueous hydrogen peroxide as a green oxidant 
in $\mathrm{CH}_{3} \mathrm{CN}$ as solvent with benzyl alcohol conversion of $96 \%$, excellent selectivity about $100 \%$, and the specific activity of this conversion was about $32 \mathrm{mmol} \cdot \mathrm{g}^{-1} \cdot \mathrm{h}^{-1}$ within $1.5 \mathrm{~h}$ under reflux conditions. Another example, Sarvari et al. [99] have prepared Nano Ag/ZnO catalyst and used for oxidant-free oxidation of benzyl alcohol to benzaldehyde. The nano $\mathrm{Ag} / \mathrm{ZnO}$ catalyst exhibited $98 \%$ benzyl alcohol conversion and more than $99 \%$ benzaldehyde selectivity along with $24.5 \mathrm{mmol} \cdot \mathrm{g}^{-1} \cdot \mathrm{h}^{-1}$ specific activity after long reaction time $8 \mathrm{~h}$ at $100{ }^{\circ} \mathrm{C}$. On the basis of these findings, it can be said that $\mathrm{ZnO}_{\mathrm{x}}(1 \%)-\mathrm{MnCO}_{3} /(1 \%) \mathrm{HRG}$ nanocomposite has found to be the best choice for the alcohol oxidation.

\subsection{Catalyst Recyclability}

The catalyst recovery has considerable importance from the both industrial and academic point of view. The recyclability of $\mathrm{ZnO}_{\mathrm{x}}(1 \%)-\mathrm{MnCO}_{3} /(1 \%) \mathrm{HRG}$ for the selective oxidation of benzyl alcohol via molecular oxygen is studied under optimized circumstances. In order to examine the reusability and stability of the as-synthesized catalyst after completion of the reaction, the toluene is evaporated and fresh toluene (solvent) is added and the mixture is filtered by simple filtration to recover the catalyst. The filtered catalyst is washed sequentially with toluene and was dried at $100{ }^{\circ} \mathrm{C}$ for $4 \mathrm{~h}$. The results obtained, (Figure 10), it is elucidated that $\mathrm{ZnO}_{x}(1 \%)-\mathrm{MnCO}_{3} /(1 \%) \mathrm{HRG}$ catalyst can be reused for at least 5 cycles without any appreciable loss of catalytic activity and benzaldehyde selectivity for all the recycle tests is found to be $>99 \%$. During the five runs investigation, the benzyl alcohol conversion decreased in a range from $100 \%$ to $93 \%$, which is probably due to the mass loss during the filtration method $[67,113]$. Therefore, results obtained indicate that our catalyst has a good reproducibility and stability.

\section{Conversion $\quad$ Selectivity}

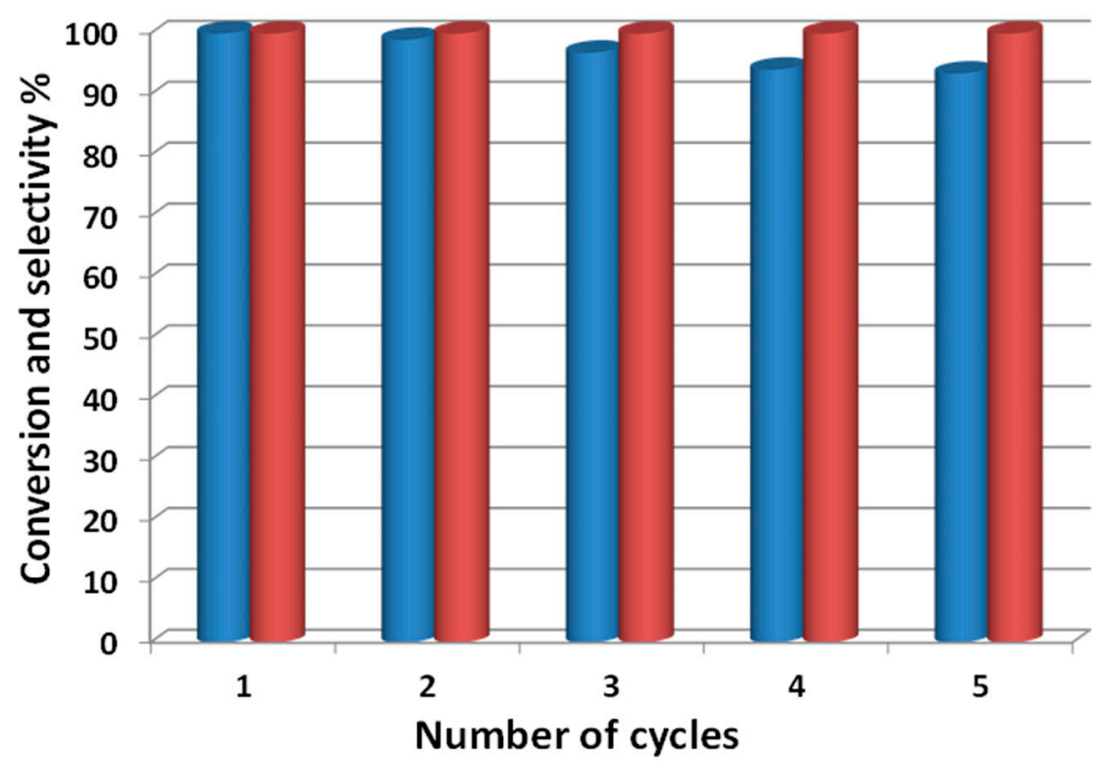

Figure 10. The recyclability $\mathrm{ZnO}_{\mathrm{x}}(1 \%)-\mathrm{MnCO}_{3} /(1 \%) \mathrm{HRG}$ catalyst in the selective oxidation of benzyl alcohol. (Reaction conditions: catalyst, $0.3 \mathrm{~g}$; benzyl alcohol, $2 \mathrm{mmol}$; calcination temperature, $300{ }^{\circ} \mathrm{C}$; reaction temperature, $100^{\circ} \mathrm{C}$; oxygen flow rate, $20 \mathrm{~mL} \cdot \mathrm{min}^{-1}$; toluene, $10 \mathrm{~mL}$; and $7 \mathrm{~min}$ reaction time).

\subsection{Oxidation of Wide Range of Benzylic and Aliphatic Alcohols}

In order to examine the general applicability and efficiency of the present catalytic protocol, oxidation of various benzylic and aliphatic alcohols were performed under the optimized conditions (Table 7). A wide range of substituted benzyl alcohols, containing 4- $\mathrm{CH}_{3}, 3-\mathrm{CH}_{3}, 2-\mathrm{CH}_{3}, 4-\mathrm{OCH}_{3}$, 3- $\mathrm{OCH}_{3}$, 2,3,4-TriOMe, 4-Cl, 2-Cl, 4- $\mathrm{Br}, 4-\mathrm{Ph}, 2,4-\mathrm{DiCl}, 4-\mathrm{NO}_{2}$, 3- $\mathrm{NO}_{2}, 2-\mathrm{NO}_{2}, 4-\mathrm{OH}, 4-\mathrm{C}\left(\mathrm{CH}_{3}\right)_{3}$, 
4- $\mathrm{CF}_{3}$, 4-F and 2,3,4,5,6-Pentaflouro groups on the phenyl ring have been easily oxidized to their corresponding aldehydes in relatively short reaction times (Table 7, entries 1-20). As mentioned in Table 7, all benzylic alcohols have selectively oxidized to corresponding aldehydes in various reactions times. A $>99 \%$ selectivity toward corresponding aldehydes have accomplished in all oxidation experiments and no by-products such as carboxylic acids were detected in the reaction mixture. It has reported that in the earlier literatures the electron-rich aromatic alcohols with electron-donating groups were found to be most reactive and exhibit shorter oxidation times whereas times for electron-withdrawing groups are longer $[112,114]$. Herein, the oxidation of benzylic alcohols bearing electron releasing substituents such as $\left(-\mathrm{CH}_{3},-\mathrm{OCH}_{3}\right.$, and $\left.-\mathrm{OH}\right)$ resulted in formation of the corresponding aldehydes with complete conversions in relatively short reaction times (Table 7, entries 2,3 and 6). The oxidation rate of the reaction is slower for derivatives of benzyl alcohol containing electron-withdrawing substituents such as $\left(-\mathrm{Cl},-\mathrm{F},-\mathrm{NO}_{2}\right.$, and $\left.-\mathrm{CF}_{3}\right)$ (Table 7, entries 9, 10, 14 and 17). Steric hindrance is also a significant factor that affects the rate of the oxidation processes, the bulky groups such as (4- $\mathrm{CF}_{3}, 2,3,4-\mathrm{TriOMe}, 2,4-\mathrm{DiCl}$, and 2,3,4,5,6-Pentaflouro) attached to the benzyl alcohol decreases the rate of oxidation reaction and required longer reaction time owing to the steric resistance that hinder the oxidation of the bulky substituents benzylic alcohols (Table 7, entries 17-20) [115]. Moreover, the results clearly revealed that the position (para-, ortho- and meta-) of electron donating groups in benzylic alcohols played also an important role in the activity of the catalytic oxidation of alcohols [85,98]. Benzylic alcohols bearing electron donating groups at para-position displayed relatively higher reactivity than the substitution in meta- and ortho-positions, because para-substituent have minimum steric hindrance in comparison to ortho and meta-substituents. For instance, the complete oxidation of para-methylbenzyl alcohol occurred within $7 \mathrm{~min}$ (Table 7, entry 3), while for meta- and ortho-methylbenzyl alcohol were completely transformed to their corresponding aldehydes after relatively longer reaction times 8 and $10 \mathrm{~min}$, respectively by compared to para-position (Table 7 , entries 4 and 7). In addition, para-substituted alcohols with electron-withdrawing groups needed longer time than those with meta- and ortho-positions, such as the complete oxidation of para-nitrobenzyl alcohol required shorter reaction time than those of meta- and ortho-nitrobenzyl alcohol (Table 7, entries 14-16). Hence, it can be said that the aerobic oxidation of substituted benzylic alcohols in presence of $\mathrm{ZnO}_{\mathrm{x}}(1 \%)-\mathrm{MnCO}_{3} /(1 \%) \mathrm{HRG}$ nanocomposite is influenced by two factors, electronic density and steric hindrance. Conversely, the oxidation of aliphatic alcohols is much more difficult than that of benzylic alcohols $[100,105]$. In this regard, the oxidation of citronellol into citronellal occurs in longer time by compared to aromatic ones, may be owing to the absence of conjugation in the $\beta$-position of the $\mathrm{OH}$ group (Table 7, entry 21). Therefore, it can be concluded that the prepared catalyst exhibited high selectivity for aromatic alcohols over aliphatic alcohols.

Table 7. Catalytic performance in the aerobic oxidation of benzylic and aliphatic alcohols.

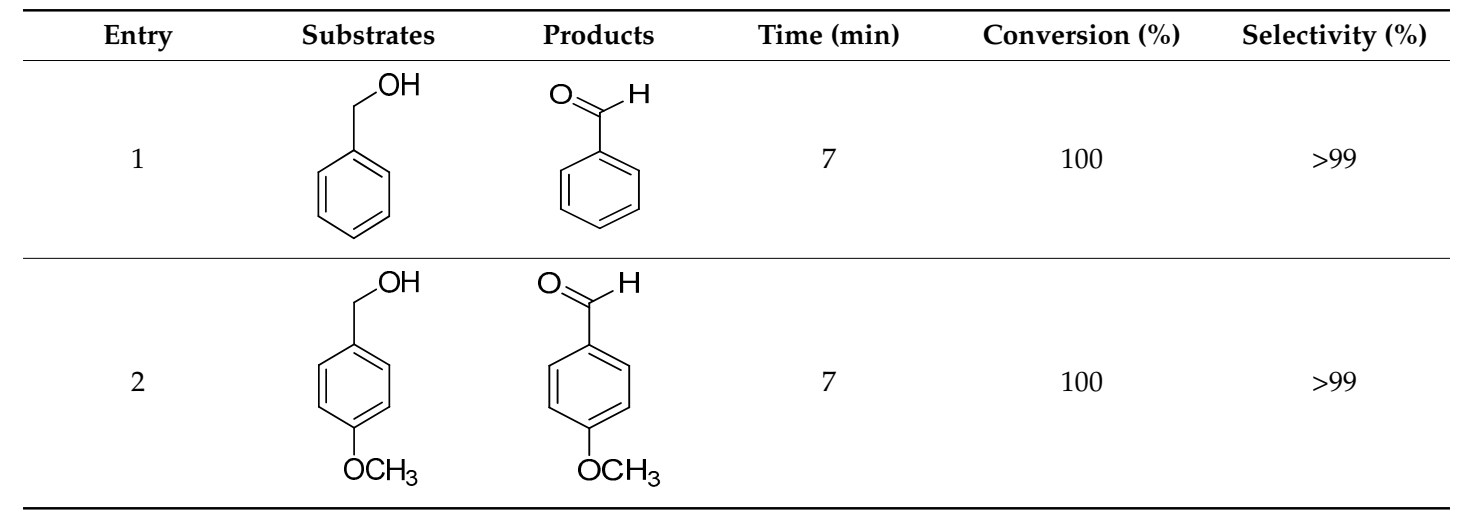


Table 7. Cont.

\begin{tabular}{|c|c|c|c|c|c|}
\hline Entry & Substrates & Products & Time (min) & Conversion (\%) & Selectivity (\%) \\
\hline 3 & & & 7 & 100 & $>99$ \\
\hline 4 & & & 8 & 100 & $>99$ \\
\hline 5 & & & 8 & 100 & $>99$ \\
\hline 6 & & & 8 & 100 & $>99$ \\
\hline 7 & & & 10 & 100 & $>99$ \\
\hline 8 & & & 9 & 100 & $>99$ \\
\hline 9 & & & 9 & 100 & $>99$ \\
\hline 10 & & & 10 & 100 & $>99$ \\
\hline 11 & & & 10 & 100 & $>99$ \\
\hline
\end{tabular}


Table 7. Cont.

\begin{tabular}{|c|c|c|c|c|c|}
\hline Entry & Substrates & Products & Time (min) & Conversion (\%) & Selectivity (\%) \\
\hline 3 & & & 7 & 100 & $>99$ \\
\hline 12 & & & 10 & 100 & $>99$ \\
\hline 13 & & & 11 & 100 & $>99$ \\
\hline 14 & & & 10 & 100 & $>99$ \\
\hline 15 & & & 12 & 100 & $>99$ \\
\hline 16 & & & 16 & 100 & $>99$ \\
\hline 17 & & & 11 & 100 & $>99$ \\
\hline 18 & & & 13 & 100 & $>99$ \\
\hline
\end{tabular}


Table 7. Cont.

Entry

Reaction conditions: alcohol, $2 \mathrm{mmol}$; toluene, $10 \mathrm{~mL}$; calcination temperature, $300{ }^{\circ} \mathrm{C}$; catalyst amount, $0.3 \mathrm{~g}$; oxygen flow rate, $20 \mathrm{~mL} \cdot \mathrm{min}^{-1}$; and reaction temperature, $100{ }^{\circ} \mathrm{C}$.

\section{Experimental Section}

\subsection{Materials}

Manganese(II) nitrate-tetrahydrate (97\%), zinc nitrate hexahydrate (99\%), Sodium bicarbonate (99\%), Toluene (98\%), Benzyl alcohol (99.5\%), 4-Methylbenzyl alcohol (99\%), 3-Methylbenzyl alcohol (99\%), 2-Methylbenzyl alcohol (99\%), 4-Methoxybenzyl alcohol (99\%), 3-Methoxybenzyl alcohol (99\%), 2,3,4-Trimethoxybenzyl alcohol (99\%), 4-Nitrobenzyl alcohol (99\%), 3-Nitrobenzyl alcohol (99\%), 2-Nitrobenzyl alcohol (99\%), 4-Chlorobenzyl alcohol (99\%), 2-Chlorobenzyl alcohol (99\%), 2,4-Dichlorobenzyl alcohol (99\%), 4-Bromobenzyl alcohol (99\%), 4-Fluorobenzyl alcohol (99\%), 4-Hydroxybenzyl alcohol (99\%), 2,3,4,5,6-Pentafluorobenzyl alcohol (99\%), 4-(Trifluoromethyl)benzyl alcohol (99\%), 4-tert-Butylbenzyl alcohol (99\%) and $\beta$-Citronellol were purchased from Sigma Aldrich (St. Louis, MO, USA).

\subsection{Synthesis of Highly Reduced Graphene Oxide (HRG)}

Firstly, graphene oxide (GO) is synthesized from graphite by the Hummers method [116]. Then, graphene oxide $(200 \mathrm{mg}$ ) is first dispersed in $40 \mathrm{~mL}$ distilled water and sonicated for $30 \mathrm{~min}$. Then the suspension will be heated to $100{ }^{\circ} \mathrm{C}$ subsequently $6 \mathrm{~mL}$ of hydrazine hydrate is added into the suspension. The suspension is then kept at $98^{\circ} \mathrm{C}$ for $24 \mathrm{~h}$. After that, the reduced graphene is collected by filtration in the form of black powders. The obtained material will then be washed using distilled water for several times to remove the excessive hydrazine and will be redistribute into water by sonication. Then the suspension will be centrifuged at $4000 \mathrm{rpm}$ for $3 \mathrm{~min}$ to remove bulk graphite. The final product is collected by vacuum filtration and dried in vacuum.

\subsection{Synthesis of $\mathrm{ZnO}_{x}(1 \%)-\mathrm{MnCO} 3 /(\mathrm{X} \%) H R G$ Nanocomposites}

$\mathrm{ZnO}_{\mathrm{x}}(1 \%)-\mathrm{MnCO}_{3} /(\mathrm{X} \%) \mathrm{HRG}$ nanocomposite is synthesized by co-precipitation method (where $\mathrm{X}=0,1,3,5$ and 7). In a typical synthesis, stoichiometric amount of manganese (II) nitrate-tetra-hydrate $\left(\mathrm{Mn}\left(\mathrm{NO}_{3}\right)_{2} \cdot 4 \mathrm{H}_{2} \mathrm{O}\right)$ and zinc nitrate hexahydrate $\left(\mathrm{Zn}\left(\mathrm{NO}_{3}\right)_{2} \cdot 6 \mathrm{H}_{2} \mathrm{O}\right)$ and highly reduced graphene oxide (HRG) were mixed in a round bottomed flask and subjected to ultrasonication for $30 \mathrm{~min}$. Then, 
the resulting solution is heated to $80^{\circ} \mathrm{C}$, while vigorously stirring using a mechanical stirrer and $0.5 \mathrm{M}$ solution of sodium bicarbonate $\left(\mathrm{NaHCO}_{3}\right)$, is added drop wise by using burette until the solution attained at $\mathrm{pH}$ 9. The solution is continued to stir at the same temperature for about $3 \mathrm{~h}$ and then left under stirring over night at room temperature. The solution is filtered using a Buchner funnel under vacuum and then dried at $70^{\circ} \mathrm{C}$ overnight in the oven. The resulting powder is then calcined at various temperatures (i.e., $300^{\circ} \mathrm{C}, 400^{\circ} \mathrm{C}$, and $500^{\circ} \mathrm{C}$ ) in the furnace for $24 \mathrm{~h}$.

\subsection{Catalyst Characterization}

Scanning electron microscopy (SEM) and elemental analysis (energy dispersive X-ray analysis: EDX) were carried out using Jeol SEM model JSM 6360A (Jeol, Akishima-shi, Japan). This is used to determine the morphology of nanoparticles and its elemental composition. Powder X-ray diffraction studies were carried out using Altima IV [Make: Regaku] X-ray diffractometer (Altima IV [Make: Regaku], Shibuya-ku, Tokyo, Japan). Fourier Transform Infrared Spectroscopy (FT-IR) the infrared spectra were recorded as KBr pellets using a Perkin-Elmer 1000 FT-IR spectrophotometer (Perkin-Elmer 1000, Waltham, MA, USA). BET surface area is measured on a NOVA 4200e surface area \& pore size analyzer (Quantachrome Instruments, FL, USA). Thermogravimetric Analysis is carried out using Perkin-Elmer Thermogravimetric Analyzer 7 (PerkinElmer, Waltham, MA, USA).

\subsection{Typical Procedure for Aerobic Oxidation of Alcohols}

Liquid-phase oxidation of benzyl alcohol as example of primary benzylic alcohols has carried out in glass flask equipped with a magnetic stirrer, reflux condenser, and thermometer. In a typical experiment, a mixture of the benzyl alcohol $(2 \mathrm{mmol})$, toluene $(10 \mathrm{~mL})$, and the catalyst $(300 \mathrm{mg})$ is transferred in a glass three-necked round-bottomed flask $(100 \mathrm{~mL})$, the resulting mixture is then heated to desired temperature with vigorous stirring. The oxidation experiment is started by bubbling oxygen gas at a flow rate of $20 \mathrm{~mL} \cdot \mathrm{min}^{-1}$ into the reaction mixture. After the reaction, the solid catalyst is filtered off by centrifugation and the liquid products were analyzed by gas chromatography to determine the conversion of the alcohol and product selectivity by GC, 7890A (Agilent Technologies Inc., Santa Clara, CA, USA) Agilent Technologies Inc., equipped with a flame ionization detector (FID) and a 19019S-001 HP-PONA column (Agilent Technologies Inc., Santa Clara, CA, USA).

\section{Conclusions}

In the present work, we have developed an efficient $\mathrm{ZnO}_{\mathrm{x}} \mathrm{NPs}$ doped $\mathrm{MnCO}_{3}$ supported on highly reduced graphene composite as an efficient catalyst for the selective oxidation of benzylic and aliphatic alcohols to corresponding carbonyls via ideal green process, i.e., under mild conditions and with molecular $\mathrm{O}_{2}$ as a green oxidant under base-free conditions. The results of oxidation prove that presence of $\mathrm{HRG}$ significantly enhance the catalytic efficiency of $\mathrm{ZnO}_{\mathrm{x}}(1 \%)-\mathrm{MnCO}_{3}$. Thus, the superior activity of the $\mathrm{ZnO}_{\mathrm{x}}(1 \%)-\mathrm{MnCO}_{3} /(1 \%) \mathrm{HRG}$ in the aerobic oxidation of alcohols should be due to the promotion role of graphene support (HRG) in the adsorption of reactant alcohol and oxygen. Typically, extremely high specific activity of $57.1 \mathrm{mmol} \cdot \mathrm{g}^{-1} \cdot \mathrm{h}^{-1}$ and complete conversion with more than $99 \%$ benzaldehyde selectivity has achieved in very short reaction time using $\mathrm{ZnO}_{\mathrm{x}}(1 \%)-\mathrm{MnCO}_{3} /(1 \%) \mathrm{HRG}$ as catalyst, which exhibits superior catalytic performance than that obtained in previous literatures. Moreover, wide range of benzylic and aliphatic alcohols has examined for selective oxidation into their corresponding carbonyl compounds and showed $100 \%$ alcohols conversion within relatively short reaction times under mild reaction conditions. The present catalytic system is very selective giving only aldehydes without over-oxidation to the carboxylic acids using only molecular $\mathrm{O}_{2}$ as oxidant without adding any additives and bases. It is noteworthy that, the oxidation rate of benzylic alcohols bearing electron donating groups higher than that containing electron withdrawing groups and bulky groups attached to benzyl alcohol decreases the oxidation rate and required longer reaction time for complete oxidation. In contrast, the oxidation of aliphatic alcohols, like citronellol, provides a relatively low conversion to citronellal, probably because of the lack of the conjugation. Additionally, 
this catalyst protocol have many advantages including, complete alcohol conversions, extremely high specific activities and selectivity towards aldehydes in very short reaction time by using an a green oxidizing agent, eco-friendly catalyst, mild conditions, low cost oxidant, low percentage of graphene, facile synthesis, heterogeneous and recyclable catalyst, will give rise to this catalyst to be a useful and applicable for the selective oxidation of alcohols.

Supplementary Materials: The following are available online at www.mdpi.com/2073-4344/7/12/391/s1, Figure S1: XRD patterns of $\mathrm{ZnO}_{\mathbf{x}}(1 \%)-\mathrm{MnCO}_{3} /(1 \%) \mathrm{HRG}$ catalyst (a) fresh and (b) recycled, Figure S2: TGA isothermal pattern of $\mathrm{ZnO}_{\mathrm{x}}(1 \%)-\mathrm{MnCO}_{3} /(1 \%) \mathrm{HRG}$ catalyst.

Acknowledgments: The authors extend their appreciation to the Deanship of Scientific Research at King Saud University for funding this work through the research group project No. RG-1436-032.

Author Contributions: Syed Farooq Adil and Mohamed E. Assal designed the project. Mohamed E. Assal, Syed Farooq Adil, Mujeeb Khan and Mohammed Rafi Shaik helped to draft the manuscript. Mohamed E. Assal, Mufsir Kuniyil and Mohammed Rafi Shaik carried out the experimental part and some part of characterization. Abdulrahman Yahya Alzahrani carried out some part of characterization. Abdulrahman Al-Warthan and Mohammed Rafiq H. Siddiqui provided scientific guidance for successful completion of the project and also helped to draft the manuscript. All authors read and approved the final manuscript.

Conflicts of Interest: The authors declare no conflict of interest.

\section{References}

1. Mallat, T.; Baiker, A. Oxidation of alcohols with molecular oxygen on solid catalysts. Chem. Rev. 2004, 104, 3037-3058. [CrossRef] [PubMed]

2. Palmisano, G.; García-López, E.; Marcì, G.; Loddo, V.; Yurdakal, S.; Augugliaro, V.; Palmisano, L. Advances in selective conversions by heterogeneous photocatalysis. Chem. Commun. 2010, 46, 7074-7089. [CrossRef] [PubMed]

3. Musawir, M.; Davey, P.N.; Kelly, G.; Kozhevnikov, I.V. Highly efficient liquid-phase oxidation of primary alcohols to aldehydes with oxygen catalysed by Ru-Co oxide. Chem. Commun. 2003, 1414-1415. [CrossRef]

4. Higashimoto, S.; Suetsugu, N.; Azuma, M.; Ohue, H.; Sakata, Y. Efficient and selective oxidation of benzylic alcohol by $\mathrm{O}_{2}$ into corresponding aldehydes on a $\mathrm{TiO}_{2}$ photocatalyst under visible light irradiation: Effect of phenyl-ring substitution on the photocatalytic activity. J. Catal. 2010, 274, 76-83. [CrossRef]

5. Zhang, M.; Wang, Q.; Chen, C.; Zang, L.; Ma, W.; Zhao, J. Oxygen atom transfer in the photocatalytic oxidation of alcohols by $\mathrm{TiO}_{2}$ : Oxygen isotope studies. Angew. Chem. Int. Ed. 2009, 48, 6081-6084. [CrossRef] [PubMed]

6. March, J. Advanced Chemistry: Reactions, Mechanisms, and Structure; John Wiley \& Sons: Hoboken, NJ, USA, 1992.

7. Enache, D.I.; Edwards, J.K.; Landon, P.; Solsona-Espriu, B.; Carley, A.F.; Herzing, A.A.; Watanabe, M.; Kiely, C.J.; Knight, D.W.; Hutchings, G.J. Solvent-free oxidation of primary alcohols to aldehydes using Au-Pd/ $\mathrm{TiO}_{2}$ catalysts. Science 2006, 311, 362-365. [CrossRef] [PubMed]

8. Ten Brink, G.-J.; Arends, I.W.; Sheldon, R.A. Green, catalytic oxidation of alcohols in water. Science 2000, 287, 1636-1639. [CrossRef] [PubMed]

9. Sheldon, R.A.; Arends, I.W.; ten Brink, G.-J.; Dijksman, A. Green, catalytic oxidations of alcohols. Acc. Chem. Res. 2002, 35, 774-781. [CrossRef] [PubMed]

10. Fox, M.A.; Dulay, M.T. Heterogeneous photocatalysis. Chem. Rev. 1993, 93, 341-357. [CrossRef]

11. Yurdakal, S.; Palmisano, G.; Loddo, V.; Augugliaro, V.; Palmisano, L. Nanostructured rutile $\mathrm{TiO}_{2}$ for selective photocatalytic oxidation of aromatic alcohols to aldehydes in water. J. Am. Chem. Soc. 2008, 130, 1568-1569. [CrossRef] [PubMed]

12. Zhan, G.; Hong, Y.; Mbah, V.T.; Huang, J.; Ibrahim, A.-R.; Du, M.; Li, Q. Bimetallic Au-Pd/MgO as efficient catalysts for aerobic oxidation of benzyl alcohol: A green bio-reducing preparation method. Appl. Catal. A 2012, 439, 179-186. [CrossRef]

13. Dell'Anna, M.M.; Mali, M.; Mastrorilli, P.; Cotugno, P.; Monopoli, A. Oxidation of benzyl alcohols to aldehydes and ketones under air in water using a polymer supported palladium catalyst. J. Mol. Catal. A Chem. 2014, 386, 114-119. [CrossRef] 
14. Kantam, M.L.; Reddy, R.S.; Pal, U.; Sudhakar, M.; Venugopal, A.; Ratnam, K.J.; Figueras, F.; Chintareddy, V.R.; Nishina, Y. Ruthenium/magnesium-lanthanum mixed oxide: An efficient reusable catalyst for oxidation of alcohols by using molecular oxygen. J. Mol. Catal. A Chem. 2012, 359, 1-7. [CrossRef]

15. Alabbad, S.; Adil, S.; Assal, M.; Khan, M.; Alwarthan, A.; Siddiqui, M.R.H. Gold \& silver nanoparticles supported on manganese oxide: Synthesis, characterization and catalytic studies for selective oxidation of benzyl alcohol. Arab. J. Chem. 2014, 7, 1192-1198.

16. Yan, Y.; Jia, X.; Yang, Y. Palladium nanoparticles supported on CNT functionalized by rare-earth oxides for solvent-free aerobic oxidation of benzyl alcohol. Catal. Today 2016, 259, 292-302. [CrossRef]

17. Zhou, C.; Guo, Z.; Dai, Y.; Jia, X.; Yu, H.; Yang, Y. Promoting role of bismuth on carbon nanotube supported platinum catalysts in aqueous phase aerobic oxidation of benzyl alcohol. Appl. Catal. B Environ. 2016, 181, 118-126. [CrossRef]

18. Komiya, N.; Nakae, T.; Sato, H.; Naota, T. Water-soluble diruthenium complexes bearing acetate and carbonate bridges: Highly efficient catalysts for aerobic oxidation of alcohols in water. Chem. Commun. 2006, 4829-4831. [CrossRef]

19. Xie, M.; Dai, X.; Meng, S.; Fu, X.; Chen, S. Selective oxidation of aromatic alcohols to corresponding aromatic aldehydes using $\mathrm{In}_{2} \mathrm{~S}_{3}$ microsphere catalyst under visible light irradiation. Chem. Eng. J. 2014, 245, 107-116. [CrossRef]

20. Choudhary, V.R.; Chaudhari, P.A.; Narkhede, V.S. Solvent-free liquid phase oxidation of benzyl alcohol to benzaldehyde by molecular oxygen using non-noble transition metal containing hydrotalcite-like solid catalysts. Catal. Commun. 2003, 4, 171-175. [CrossRef]

21. Mahdavi, V.; Hasheminasab, H.R. Vanadium phosphorus oxide catalyst promoted by cobalt doping for mild oxidation of benzyl alcohol to benzaldehyde in the liquid phase. Appl. Catal. A 2014, 482, 189-197. [CrossRef]

22. Ji, H.-B.; Wang, T.-T.; Zhang, M.-Y.; Chen, Q.-L.; Gao, X.-N. Green oxidation of alcohols by a reusable nickel catalyst in the presence of molecular oxygen. React. Kinet. Catal. Lett. 2007, 90, 251-257. [CrossRef]

23. Cang, R.; Lu, B.; Li, X.; Niu, R.; Zhao, J.; Cai, Q. Iron-chloride ionic liquid immobilized on SBA-15 for solvent-free oxidation of benzyl alcohol to benzaldehyde with $\mathrm{H}_{2} \mathrm{O}_{2}$. Chem. Eng. Sci. 2015, 137, 268-275. [CrossRef]

24. Behera, G.C.; Parida, K. Liquid phase catalytic oxidation of benzyl alcohol to benzaldehyde over vanadium phosphate catalyst. Appl. Catal. A 2012, 413, 245-253. [CrossRef]

25. Adil, S.F.; Assal, M.E.; Khan, M.; Al-Warthan, A.; Siddiqui, M.R.H. Nano Silver-Doped Manganese Oxide as Catalyst for Oxidation of Benzyl Alcohol and Its Derivatives: Synthesis, Characterisation, Thermal Study and Evaluation of Catalytic Properties. Oxid. Commun. 2013, 36, 778-791.

26. Öztürk, Ö.F.; Zümreoğlu-Karan, B.; Karabulut, S. Solvent-free oxidation of benzyl alcohol over chromium orthoborate. Catal. Commun. 2008, 9, 1644-1648. [CrossRef]

27. Biradar, A.V.; Dongare, M.K.; Umbarkar, S.B. Selective oxidation of aromatic primary alcohols to aldehydes using molybdenum acetylide oxo-peroxo complex as catalyst. Tetrahedron Lett. 2009, 50, 2885-2888. [CrossRef]

28. Sousa, S.C.; Bernardo, J.R.; Florindo, P.R.; Fernandes, A.C. Efficient and selective oxidation of alcohols catalyzed by oxo-rhenium complexes. Catal. Commun. 2013, 40, 134-138. [CrossRef]

29. Goh, T.W.; Xiao, C.; Maligal-Ganesh, R.V.; Li, X.; Huang, W. Utilizing mixed-linker zirconium-based metal-organic frameworks to enhance the visible light photocatalytic oxidation of alcohol. Chem. Eng. Sci. 2015, 124, 45-51. [CrossRef]

30. Adil, S.F.; Alabbad, S.; Kuniyil, M.; Khan, M.; Alwarthan, A.; Mohri, N.; Tremel, W.; Tahir, M.N.; Siddiqui, M.R.H. Vanadia supported on nickel manganese oxide nanocatalysts for the catalytic oxidation of aromatic alcohols. Nanoscale Res. Lett. 2015, 10, 1-9. [CrossRef] [PubMed]

31. Tang, Q.; Gong, X.; Zhao, P.; Chen, Y.; Yang, Y. Copper-manganese oxide catalysts supported on alumina: Physicochemical features and catalytic performances in the aerobic oxidation of benzyl alcohol. Appl. Catal. A 2010, 389, 101-107. [CrossRef]

32. Arena, F.; Gumina, B.; Lombardo, A.F.; Espro, C.; Patti, A.; Spadaro, L.; Spiccia, L. Nanostructured $\mathrm{MnO}_{\mathrm{x}}$ catalysts in the liquid phase selective oxidation of benzyl alcohol with oxygen: Part I. Effects of Ce and Fe addition on structure and reactivity. Appl. Catal. B Environ. 2015, 162, 260-267. [CrossRef] 
33. Clarke, T.J.; Kondrat, S.A.; Taylor, S.H. Total oxidation of naphthalene using copper manganese oxide catalysts. Catal. Today 2015, 258, 610-615. [CrossRef]

34. Tepluchin, M.; Kureti, S.; Casapu, M.; Ogel, E.; Mangold, S.; Grunwaldt, J.-D. Study on the hydrothermal and $\mathrm{SO}_{2}$ stability of $\mathrm{Al}_{2} \mathrm{O}_{3}$-supported manganese and iron oxide catalysts for lean $\mathrm{CO}$ oxidation. Catal. Today 2015, 258, 498-506. [CrossRef]

35. Kim, S.C.; Park, Y.-K.; Nah, J.W. Property of a highly active bimetallic catalyst based on a supported manganese oxide for the complete oxidation of toluene. Powder Technol. 2014, 266, 292-298. [CrossRef]

36. Ashouri, F.; Zare, M.; Bagherzade, M. Manganese and cobalt-terephthalate metal-organic frameworks as a precursor for synthesis of $\mathrm{Mn}_{2} \mathrm{O}_{3}, \mathrm{Mn}_{3} \mathrm{O}_{4}$ and $\mathrm{Co}_{3} \mathrm{O}_{4}$ nanoparticles: Active catalysts for olefin heterogeneous oxidation. Inorg. Chem. Commun. 2015, 61, 73-76. [CrossRef]

37. Piumetti, M.; Fino, D.; Russo, N. Mesoporous manganese oxides prepared by solution combustion synthesis as catalysts for the total oxidation of VOCs. Appl. Catal. B Environ. 2015, 163, 277-287. [CrossRef]

38. Feng, Z.; Xie, Y.; Hao, F.; Liu, P.; Luo, H.A. Catalytic oxidation of cyclohexane to KA oil by zinc oxide supported manganese 5, 10, 15, 20-tetrakis (4-nitrophenyl) porphyrin. J. Mol. Catal. A Chem. 2015, 410, 221-225. [CrossRef]

39. Einaga, H.; Yamamoto, S.; Maeda, N.; Teraoka, Y. Structural analysis of manganese oxides supported on $\mathrm{SiO}_{2}$ for benzene oxidation with ozone. Catal. Today 2015, 242, 287-293. [CrossRef]

40. Burange, A.S.; Kale, S.R.; Jayaram, R.V. Oxidation of alkyl aromatics to ketones by tert-butyl hydroperoxide on manganese dioxide catalyst. Tetrahedron Lett. 2012, 53, 2989-2992. [CrossRef]

41. Qi, G.; Li, W. NO oxidation to $\mathrm{NO}_{2}$ over manganese-cerium mixed oxides. Catal. Today 2015, 258, $205-213$. [CrossRef]

42. Yu, W.; Zhou, C.; Tong, D.; Xu, T. Aerobic oxidation of 4-tert-butyltoluene over cobalt and manganese supported hexagonal mesoporous silicas as heterogeneous catalysts. J. Mol. Catal. A Chem. 2012, 365, 194-202. [CrossRef]

43. Pei, J.; Han, X.; Lu, Y. Performance and kinetics of catalytic oxidation of formaldehyde over copper manganese oxide catalyst. Build. Environ. 2015, 84, 134-141. [CrossRef]

44. Rao, C.N.R.; Sood, A.K.; Subrahmanyam, K.S.; Govindaraj, A. Graphene: The new two-dimensional nanomaterial. Angew. Chem. Int. Ed. 2009, 48, 7752-7777. [CrossRef] [PubMed]

45. Lee, J.W.; Ahn, T.; Soundararajan, D.; Ko, J.M.; Kim, J.-D. Non-aqueous approach to the preparation of reduced graphene oxide $/ \alpha-\mathrm{Ni}(\mathrm{OH})_{2}$ hybrid composites and their high capacitance behavior. Chem. Commun. 2011, 47, 6305-6307. [CrossRef] [PubMed]

46. Yan, J.; Fan, Z.; Wei, T.; Qian, W.; Zhang, M.; Wei, F. Fast and reversible surface redox reaction of graphene- $\mathrm{MnO}_{2}$ composites as supercapacitor electrodes. Carbon 2010, 48, 3825-3833. [CrossRef]

47. Cheng, Q.; Tang, J.; Ma, J.; Zhang, H.; Shinya, N.; Qin, L.-C. Graphene and nanostructured $\mathrm{MnO}_{2}$ composite electrodes for supercapacitors. Carbon 2011, 49, 2917-2925. [CrossRef]

48. Chandra, S.; Bag, S.; Bhar, R.; Pramanik, P. Sonochemical synthesis and application of rhodium-graphene nanocomposite. J. Nanopart. Res. 2011, 13, 2769-2777. [CrossRef]

49. Sreeprasad, T.; Maliyekkal, S.M.; Lisha, K.; Pradeep, T. Reduced graphene oxide-metal/metal oxide composites: Facile synthesis and application in water purification. J. Hazard. Mater. 2011, 186, 921-931. [CrossRef] [PubMed]

50. Fan, X.; Jiao, G.; Gao, L.; Jin, P.; Li, X. The preparation and drug delivery of a graphene-carbon nanotube- $\mathrm{Fe}_{3} \mathrm{O}_{4}$ nanoparticle hybrid. J. Mater. Chem. B 2013, 1, 2658-2664. [CrossRef]

51. Zhao, L.; Li, H.; Gao, S.; Li, M.; Xu, S.; Li, C.; Guo, W.; Qu, C.; Yang, B. MgO nanobelt-modified graphene-tantalum wire electrode for the simultaneous determination of ascorbic acid, dopamine and uric acid. Electrochim. Acta 2015, 168, 191-198. [CrossRef]

52. Al-Marri, A.H.; Khan, M.; Shaik, M.R.; Mohri, N.; Adil, S.F.; Kuniyil, M.; Alkhathlan, H.Z.; Al-Warthan, A.; Tremel, W.; Tahir, M.N. Green synthesis of Pd@ graphene nanocomposite: Catalyst for the selective oxidation of alcohols. Arab. J. Chem. 2016, 9, 835-845. [CrossRef]

53. Mahyari, M.; Shaabani, A. Graphene oxide-iron phthalocyanine catalyzed aerobic oxidation of alcohols. Appl. Catal. A 2014, 469, 524-531. [CrossRef]

54. Kadam, M.M.; Dhopte, K.B.; Jha, N.; Gaikar, V.G.; Nemade, P.R. Synthesis, characterization and application of $\gamma-\mathrm{MnO}_{2}$ /graphene oxide for the selective aerobic oxidation of benzyl alcohols to corresponding carbonyl compounds. New J. Chem. 2016, 40, 1436-1442. [CrossRef] 
55. Zahed, B.; Hosseini-Monfared, H. A comparative study of silver-graphene oxide nanocomposites as a recyclable catalyst for the aerobic oxidation of benzyl alcohol: Support effect. Appl. Surf. Sci. 2015, 328, 536-547. [CrossRef]

56. Yu, X.; Huo, Y.; Yang, J.; Chang, S.; Ma, Y.; Huang, W. Reduced graphene oxide supported Au nanoparticles as an efficient catalyst for aerobic oxidation of benzyl alcohol. Appl. Surf. Sci. 2013, 280, 450-455. [CrossRef]

57. Li, F.; Guo, Y.; Wu, T.; Liu, Y.; Wang, W.; Gao, J. Platinum nano-catalysts deposited on reduced graphene oxides for alcohol oxidation. Electrochim. Acta 2013, 111, 614-620. [CrossRef]

58. Jha, A.; Mhamane, D.; Suryawanshi, A.; Joshi, S.M.; Shaikh, P.; Biradar, N.; Ogale, S.; Rode, C.V. Triple nanocomposites of $\mathrm{CoMn}_{2} \mathrm{O}_{4}, \mathrm{Co}_{3} \mathrm{O}_{4}$ and reduced graphene oxide for oxidation of aromatic alcohols. Catal. Sci. Technol. 2014, 4, 1771-1778. [CrossRef]

59. Wu, S.; He, Q.; Zhou, C.; Qi, X.; Huang, X.; Yin, Z.; Yang, Y.; Zhang, H. Synthesis of $\mathrm{Fe}_{3} \mathrm{O}_{4}$ and Pt nanoparticles on reduced graphene oxide and their use as a recyclable catalyst. Nanoscale 2012, 4, 2478-2483. [CrossRef] [PubMed]

60. Yang, M.-Q.; Zhang, N.; Xu, Y.-J. Synthesis of fullerene-, carbon nanotube-, and graphene-TiO 2 nanocomposite photocatalysts for selective oxidation: A comparative study. ACS Appl. Mater. Interfaces 2013, 5, 1156-1164. [CrossRef] [PubMed]

61. Wang, J.; Kondrat, S.A.; Wang, Y.; Brett, G.L.; Giles, C.; Bartley, J.K.; Lu, L.; Liu, Q.; Kiely, C.J.; Hutchings, G.J. $\mathrm{Au}-\mathrm{Pd}$ Nanoparticles Dispersed on Composite Titania/Graphene Oxide-Supports as a Highly Active Oxidation Catalyst. ACS Catal. 2015, 5, 3575-3587. [CrossRef]

62. Assal, M.E.; Kuniyil, M.; Shaik, M.R.; Khan, M.; Al-Warthan, A.; Siddiqui, M.R.H.; Adil, S.F. Synthesis, Characterization, and Relative Study on the Catalytic Activity of Zinc Oxide Nanoparticles Doped $\mathrm{MnCO}_{3}$, $-\mathrm{MnO}_{2}$, and $-\mathrm{Mn}_{2} \mathrm{O}_{3}$ Nanocomposites for Aerial Oxidation of Alcohols. J. Chem. 2017, 2017. [CrossRef]

63. Wang, H.; Hu, Y.H. Effect of oxygen content on structures of graphite oxides. Ind. Eng. Chem. Res. 2011, 50, 6132-6137. [CrossRef]

64. Yang, S.; Lin, Y.; Song, X.; Zhang, P.; Gao, L. Covalently coupled ultrafine $\mathrm{H}_{-} \mathrm{TiO}_{2}$ nanocrystals/nitrogen-doped graphene hybrid materials for high-performance supercapacitor. ACS Appl. Mater. Interfaces 2015, 7, 17884-17892. [CrossRef] [PubMed]

65. Mirza-Aghayan, M.; Kashef-Azar, E.; Boukherroub, R. Graphite oxide: An efficient reagent for oxidation of alcohols under sonication. Tetrahedron Lett. 2012, 53, 4962-4965. [CrossRef]

66. Zhang, S.; Zhu, L.; Song, H.; Chen, X.; Wu, B.; Zhou, J.; Wang, F. How graphene is exfoliated from graphitic materials: Synergistic effect of oxidation and intercalation processes in open, semi-closed, and closed carbon systems. J. Mater. Chem. 2012, 22, 22150-22154. [CrossRef]

67. Zhong, J.; Bin, D.; Ren, F.; Wang, C.; Zhai, C.; Yang, P.; Du, Y. Graphene nanosheet-supported Pd nano-leaves with highly efficient electrocatalytic performance for formic acid oxidation. Colloids Surf. A 2016, 488, 1-6. [CrossRef]

68. Adil, S.F.; Assal, M.E.; Kuniyil, M.; Khan, M.; Shaik, M.R.; Alwarthan, A.; Labis, J.P.; Siddiqui, M.R.H. Synthesis and comparative catalytic study of zinc oxide $\left(\mathrm{ZnO}_{\mathrm{x}}\right)$ nanoparticles promoted $\mathrm{MnCO}_{3}, \mathrm{MnO}_{2}$ and $\mathrm{Mn}_{2} \mathrm{O}_{3}$ for selective oxidation of benzylic alcohols using molecular oxygen. Mater. Express 2017, 7, 79-92. [CrossRef]

69. Sharma, P.; Darabdhara, G.; Reddy, T.M.; Borah, A.; Bezboruah, P.; Gogoi, P.; Hussain, N.; Sengupta, P.; Das, M.R. Synthesis, characterization and catalytic application of Au NPs-reduced graphene oxide composites material: An eco-friendly approach. Catal. Commun. 2013, 40, 139-144. [CrossRef]

70. Santra, S.; Hota, P.K.; Bhattacharyya, R.; Bera, P.; Ghosh, P.; Mandal, S.K. Palladium nanoparticles on graphite oxide: A recyclable catalyst for the synthesis of biaryl cores. ACS Catal. 2013, 3, 2776-2789. [CrossRef]

71. Stankovich, S.; Dikin, D.A.; Piner, R.D.; Kohlhaas, K.A.; Kleinhammes, A.; Jia, Y.; Wu, Y.; Nguyen, S.T.; Ruoff, R.S. Synthesis of graphene-based nanosheets via chemical reduction of exfoliated graphite oxide. Carbon 2007, 45, 1558-1565. [CrossRef]

72. Lerf, A.; He, H.; Forster, M.; Klinowski, J. Structure of graphite oxide revisited. J. Phys. Chem. B 1998, 102, 4477-4482. [CrossRef]

73. Wang, Z.-L.; Xu, D.; Huang, Y.; Wu, Z.; Wang, L.-M.; Zhang, X.-B. Facile, mild and fast thermal-decomposition reduction of graphene oxide in air and its application in high-performance lithium batteries. Chem. Commun. 2012, 48, 976-978. [CrossRef] [PubMed] 
74. Metin, Ö.; Kayhan, E.; Özkar, S.; Schneider, J.J. Palladium nanoparticles supported on chemically derived graphene: An efficient and reusable catalyst for the dehydrogenation of ammonia borane. Int. J. Hydrogen Energy 2012, 37, 8161-8169. [CrossRef]

75. Geng, L.; Wu, S.; Zou, Y.; Jia, M.; Zhang, W.; Yan, W.; Liu, G. Correlation between the microstructures of graphite oxides and their catalytic behaviors in air oxidation of benzyl alcohol. J. Colloid Interface Sci. 2014, 421, 71-77. [CrossRef] [PubMed]

76. Wang, Y.; Zhao, Y.; He, W.; Yin, J.; Su, Y. Palladium nanoparticles supported on reduced graphene oxide: Facile synthesis and highly efficient electrocatalytic performance for methanol oxidation. Thin Solid Films 2013, 544, 88-92. [CrossRef]

77. Hou, S.; Su, S.; Kasner, M.L.; Shah, P.; Patel, K.; Madarang, C.J. Formation of highly stable dispersions of silane-functionalized reduced graphene oxide. Chem. Phys. Lett. 2010, 501, 68-74. [CrossRef]

78. Kadam, M.M.; Sravani, M.B.; Gaikar, V.; Jha, N. Synthesis and fabrication of graphene oxide thin film. In Proceedings of the CARBON MATERIALS 2012 (CCM12): Carbon Materials for Energy Harvesting, Environment, Nanoscience and Technology, Mumbai, India, 1-3 November 2012; AIP Publishing: Melville, NY, USA, 2013; pp. 249-252.

79. Sitko, R.; Turek, E.; Zawisza, B.; Malicka, E.; Talik, E.; Heimann, J.; Gagor, A.; Feist, B.; Wrzalik, R. Adsorption of divalent metal ions from aqueous solutions using graphene oxide. Dalton Trans. 2013, 42, 5682-5689. [CrossRef] [PubMed]

80. Miao, M.; Feng, J.; Jin, Q.; He, Y.; Liu, Y.; Du, Y.; Zhang, N.; Li, D. Hybrid Ni-Al layered double hydroxide/graphene composite supported gold nanoparticles for aerobic selective oxidation of benzyl alcohol. RSC Adv. 2015, 5, 36066-36074. [CrossRef]

81. Wojtoniszak, M.; Mijowska, E. Controlled oxidation of graphite to graphene oxide with novel oxidants in a bulk scale. J. Nanopart. Res. 2012, 14, 1248. [CrossRef] [PubMed]

82. Gao, L.; Yue, W.; Tao, S.; Fan, L. Novel strategy for preparation of graphene-Pd, Pt composite, and its enhanced electrocatalytic activity for alcohol oxidation. Langmuir 2013, 29, 957-964. [CrossRef] [PubMed]

83. Hu, H.; Xu, J.-Y.; Yang, H.; Liang, J.; Yang, S.; Wu, H. Morphology-controlled hydrothermal synthesis of $\mathrm{MnCO}_{3}$ hierarchical superstructures with Schiff base as stabilizer. Mater. Res. Bull. 2011, 46, 1908-1915. [CrossRef]

84. Wu, S.; Cao, H.; Yin, S.; Zhang, X.; Chernow, V. Biomineralization and superhydrophobicity of $\mathrm{BaCO}_{3}$ complex nanostructures. Inorg. Chem. 2009, 48, 10326-10329. [CrossRef] [PubMed]

85. Xie, W.; Zhang, F.; Wang, Z.; Yang, M.; Xia, J.; Gui, R.; Xia, Y. Facile preparation of PtPdPt/graphene nanocomposites with ultrahigh electrocatalytic performance for methanol oxidation. J. Electroanal. Chem. 2016, 761, 55-61. [CrossRef]

86. Qiu, T.; Wang, J.; Lu, Y.; Yang, W. Facile fabrication of Chinese lantern-like MnO@ N-C: A high-performance anode material for lithium-ion batteries. RSC Adv. 2014, 4, 23027-23035. [CrossRef]

87. Ferrari, A.C.; Robertson, J. Interpretation of Raman spectra of disordered and amorphous carbon. Phys. Rev. B 2000, 61, 14095. [CrossRef]

88. Gil, S.; Muñoz, L.; Sánchez-Silva, L.; Romero, A.; Valverde, J.L. Synthesis and characterization of Au supported on carbonaceous material-based catalysts for the selective oxidation of glycerol. Chem. Eng. J. 2011, 172, 418-429. [CrossRef]

89. Nie, R.; Wang, J.; Wang, L.; Qin, Y.; Chen, P.; Hou, Z. Platinum supported on reduced graphene oxide as a catalyst for hydrogenation of nitroarenes. Carbon 2012, 50, 586-596. [CrossRef]

90. Gurunathan, S.; Han, J.W.; Eppakayala, V.; Kim, J.-H. Microbial reduction of graphene oxide by Escherichia coli: A green chemistry approach. Colloids Surf. B 2013, 102, 772-777. [CrossRef] [PubMed]

91. Qusti, A.; Mohamed, R.; Salam, M.A. Photocatalytic synthesis of aniline from nitrobenzene using Ag-reduced graphene oxide nanocomposite. Ceram. Int. 2014, 40, 5539-5546. [CrossRef]

92. Liu, L.; Lin, X.-X.; Zou, S.-Y.; Wang, A.-J.; Chen, J.-R.; Feng, J.-J. One-pot wet-chemical synthesis of PtPd@ Pt nanocrystals supported on reduced graphene oxide with highly electrocatalytic performance for ethylene glycol oxidation. Electrochim. Acta 2016, 187, 576-583. [CrossRef]

93. Ensafi, A.A.; Ahmadi, Z.; Jafari-Asl, M.; Rezaei, B. Graphene nanosheets functionalized with Nile blue as a stable support for the oxidation of glucose and reduction of oxygen based on redox replacement of Pd-nanoparticles via nickel oxide. Electrochim. Acta 2015, 173, 619-629. [CrossRef] 
94. Nişanc1, B.; Ganjehyan, K.; Metin, Ö.; Daştan, A.; Török, B. Graphene-supported NiPd alloy nanoparticles: A novel and highly efficient heterogeneous catalyst system for the reductive amination of aldehydes. J. Mol. Catal. A Chem. 2015, 409, 191-197. [CrossRef]

95. Mirza-Aghayan, M.; Tavana, M.M.; Boukherroub, R. Palladium nanoparticles supported on reduced graphene oxide as an efficient catalyst for the reduction of benzyl alcohol compounds. Catal. Commun. 2015, 69, 97-103. [CrossRef]

96. Rana, S.; Maddila, S.; Yalagala, K.; Jonnalagadda, S.B. Organo functionalized graphene with Pd nanoparticles and its excellent catalytic activity for Suzuki coupling reaction. Appl. Catal. A 2015, 505, 539-547. [CrossRef]

97. Sreethawong, T.; Ngamsinlapasathian, S.; Yoshikawa, S. Facile surfactant-aided sol-gel synthesis of mesoporous-assembled $\mathrm{Ta}_{2} \mathrm{O}_{5}$ nanoparticles with enhanced photocatalytic $\mathrm{H}_{2}$ production. J. Mol. Catal. A Chem. 2013, 374, 94-101. [CrossRef]

98. Heidari-Golafzani, M.; Rabbani, M.; Rahimi, R.; Azad, A. Catalytic oxidation of primary and secondary alcohols over a novel TCPP/Zn-Fe $\mathrm{O}_{4} @ \mathrm{ZnO}$ catalyst. RSC Adv. 2015, 5, 99640-99645. [CrossRef]

99. Hosseini-Sarvari, M.; Ataee-Kachouei, T.; Moeini, F. A novel and active catalyst Ag/ZnO for oxidant-free dehydrogenation of alcohols. Mater. Res. Bull. 2015, 72, 98-105. [CrossRef]

100. Hasannia, S.; Yadollahi, B. Zn-Al LDH nanostructures pillared by Fe substituted Keggin type polyoxometalate: Synthesis, characterization and catalytic effect in green oxidation of alcohols. Polyhedron 2015, 99, 260-265. [CrossRef]

101. Chen, Z.; Xu, J.; Ren, Z.; He, Y.; Xiao, G. High efficient photocatalytic selective oxidation of benzyl alcohol to benzaldehyde by solvothermal-synthesized $\mathrm{ZnIn}_{2} \mathrm{~S}_{4}$ microspheres under visible light irradiation. J. Solid State Chem. 2013, 205, 134-141. [CrossRef]

102. Albadi, J.; Alihoseinzadeh, A.; Razeghi, A. Novel metal oxide nanocomposite of Au/CuO-ZnO for recyclable catalytic aerobic oxidation of alcohols in water. Catal. Commun. 2014, 49, 1-5. [CrossRef]

103. Ede, S.R.; Ramadoss, A.; Nithiyanantham, U.; Anantharaj, S.; Kundu, S. Bio-molecule assisted aggregation of $\mathrm{ZnWO}_{4}$ nanoparticles (NPs) into chain-like assemblies: Material for high performance supercapacitor and as catalyst for benzyl alcohol oxidation. Inorg. Chem 2015, 54, 3851-3863. [CrossRef] [PubMed]

104. Nadealian, Z.; Mirkhani, V.; Yadollahi, B.; Moghadam, M.; Tangestaninejad, S.; Mohammadpoor-Baltork, I. Selective oxidation of alcohols to aldehydes using inorganic-organic hybrid catalyst based on zinc substituted polyoxometalate and ionic liquid. J. Coord. Chem. 2012, 65, 1071-1081. [CrossRef]

105. Assady, E.; Yadollahi, B.; Riahi Farsani, M.; Moghadam, M. Zinc polyoxometalate on activated carbon: An efficient catalyst for selective oxidation of alcohols with hydrogen peroxide. Appl. Organomet. Chem. 2015, 29, 561-565. [CrossRef]

106. Kumar, R.T.; Selvam, N.C.S.; Ragupathi, C.; Kennedy, L.J.; Vijaya, J.J. Synthesis, characterization and performance of porous $\mathrm{Sr}(\mathrm{II})$-added $\mathrm{ZnAl}_{2} \mathrm{O}_{4}$ nanomaterials for optical and catalytic applications. Powder Technol. 2012, 224, 147-154. [CrossRef]

107. Wu, X.F. A General and Efficient Zinc-Catalyzed Oxidation of Benzyl Alcohols to Aldehydes and Esters. Chem. Eur. J. 2012, 18, 8912-8915. [CrossRef] [PubMed]

108. Tian, W.; Hou, Y.; Wang, X.; Lu, B.; Zhao, J.; Cai, Q. A Simple Polyoxometallate for Selective Oxidation of Benzyl Alcohol to Benzaldehyde with Hydrogen Peroxide. Chin. J. Chem. 2012, 30, 433-437. [CrossRef]

109. Burange, A.S.; Kale, S.R.; Zboril, R.; Gawande, M.B.; Jayaram, R.V. Magnetically retrievable $\mathrm{MFe}_{2} \mathrm{O}_{4}$ spinel $(\mathrm{M}=\mathrm{Mn}, \mathrm{Co}, \mathrm{Cu}, \mathrm{Ni}, \mathrm{Zn})$ catalysts for oxidation of benzylic alcohols to carbonyls. RSC Adv. 2014, 4, 6597-6601. [CrossRef]

110. Choudhary, V.; Dumbre, D.; Uphade, B.; Narkhede, V. Solvent-free oxidation of benzyl alcohol to benzaldehyde by tert-butyl hydroperoxide using transition metal containing layered double hydroxides and/or mixed hydroxides. J. Mol. Catal. A Chem. 2004, 215, 129-135. [CrossRef]

111. Nadealian, Z.; Mirkhani, V.; Yadollahi, B.; Moghadam, M.; Tangestaninejad, S.; Mohammadpoor-Baltork, I. Green and efficient oxidation of benzylic alcohols with hydrogen peroxide catalyzed by an inorganic-organic hybrid catalyst. J. Coord. Chem. 2013, 66, 1264-1275. [CrossRef]

112. Yan, K.; Wu, X.; An, X.; Xie, X. Facile synthesis and catalytic property of spinel ferrites by a template method. J. Alloys Compd. 2013, 552, 405-408. [CrossRef]

113. Dreyer, D.R.; Park, S.; Bielawski, C.W.; Ruoff, R.S. The chemistry of graphene oxide. Chem. Soc. Rev. 2010, 39, 228-240. [CrossRef] [PubMed] 
114. Peterson, K.P.; Larock, R.C. Palladium-catalyzed oxidation of primary and secondary allylic and benzylic alcohols. J. Org. Chem. 1998, 63, 3185-3189. [CrossRef]

115. Borthakur, R.; Asthana, M.; Kumar, A.; Lal, R.A. Cooperative catalysis by polymetallic copper-zinc complexes in the efficient oxidation of alcohols under solvent free condition. Inorg. Chem. Commun. 2014, 46, 198-201. [CrossRef]

116. Hummers, W.S., Jr.; Offeman, R.E. Preparation of graphitic oxide. J. Am. Chem. Soc. 1958, 80, 1339. [CrossRef]

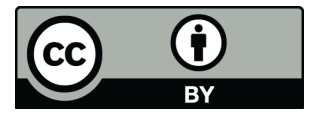

(C) 2017 by the authors. Licensee MDPI, Basel, Switzerland. This article is an open access article distributed under the terms and conditions of the Creative Commons Attribution (CC BY) license (http:/ / creativecommons.org/licenses/by/4.0/). 